\title{
ACERCAMIENTO AL ESTUDIO DE LOS SISTEMAS DE CARGOS ENTRE LAS COMUNIDADES HUICHOLAS DE JALISCO Y NAYARIT, MÉXICO
}

\author{
AN APPROACH TO THE STUDY OF SOCIAL STRUCTURE AMONG \\ THE HUICHOL PEOPLE OF JALISCO AND NAYARIT, MEXICO
}

Víctor Manuel Téllez Lozano*

Para Phil Weigand, maestro y amigo, in memoriam

\begin{abstract}
Existe una amplia bibliografía para el análisis de los sistemas de cargos en diferentes regiones indígenas de México. Sin embargo, el estudio de las formas de gobierno entre los huicholes se ha visto limitado por una visión exótica de la cultura que pasa por alto la información generada a lo largo del periodo colonial y la etnográfica vertida desde finales del siglo XIX.

Entre las comunidades huicholas de la zona del río Chapalagana, la jerarquía cívico-religiosa instituida durante el periodo colonial es el fundamento de un modelo de sociedad igualitaria. Sin embargo, este modelo fue establecido sobre la base de una estructura política previa y de carácter mesoamericano. En este trabajo se analiza, a partir de la información etnográfica disponible, la forma en que las instituciones de origen prehispánico y colonial han logrado subsistir hasta nuestros días, así como las adaptaciones que les han permitido subsistir, a veces sobreponiéndose y otras articulándose a las instituciones creadas por el Estado mexicano.

Palabras claves: Sistemas de cargos, organización política y ceremonial, huicholes.
\end{abstract}

The bibliography dealing with analyses of cargo systems in different indigenous regions of Mexico is ample indeed. However, studies of the forms of government among the Huicholes have been constrained by an exotic vision of culture that tends to overlook the information generated during the Colonial period and the ethnographic contributions made since the late $19^{\text {th }}$ century. Among the Huichol communities in the zone around the Chapalagana River, the civil-religious hierarchy instituted in Colonial times constitutes the foundations of a model of an egalitarian society. But, of course, this model was established on the base of an earlier political structure of a Mesoamerican character. In light of these antecedents, and based on the ethnographic information available, this study analyzes how institutions of pre-Hispanic and Colonial origin have managed to subsist up to the present, and the adaptations that have made their survival possible; at times through superimposition upon the institutions created by the Mexican State, at others through articulations with them.

Key words: Cargo systems, political and ceremonial organization, Huichol indians.

\section{Introducción}

Entre las comunidades Huicholas de la zona del río Chapalagana, las jerarquías civiles y religiosas instituidas durante el periodo colonial representan el fundamento de un modelo de sociedad igualitaria. Sin embargo, este modelo fue establecido sobre la base de una estructura política previa y de carácter mesoamericano. En este trabajo se analiza, a partir de la información etnográfica disponible, la forma en que las instituciones de origen prehispánico y colonial han logrado subsistir hasta nuestros días, así como las adaptaciones que les han permitido sobrevivir, a veces sobreponiéndose y otras articulándose con las instituciones creadas por el Estado mexicano.
Este trabajo se basa en la información disponible sobre las comunidades de Santa Catarina Cuexcomatitlán, San Sebastián Teponahuaxtlán y San Andrés Cohamiata, así como las subcomunidades de Guadalupe Ocotán (antiguo anexo de San Andrés Cohamiata) y Tuxpan de Bolaños (anexo de San Sebastián Teponahuaxtlán) (Mapas 1 y 2). Estas últimas fueron demarcaciones surgidas a partir de las presiones ejercidas por el avance de las haciendas y establecimientos mineros sobre el territorio huichol desde finales del siglo XVIII, pero especialmente por las campañas emprendidas por los misioneros franciscanos a mediados del siglo XIX, lo que representó un proceso de reorganización territorial, pero también la instauración de jerarquías

\footnotetext{
* Universidad de Guadalajara, Departamento de Estudios Socio Urbanos, México. Correo electrónico: victortellez2011@ gmail.com
} 


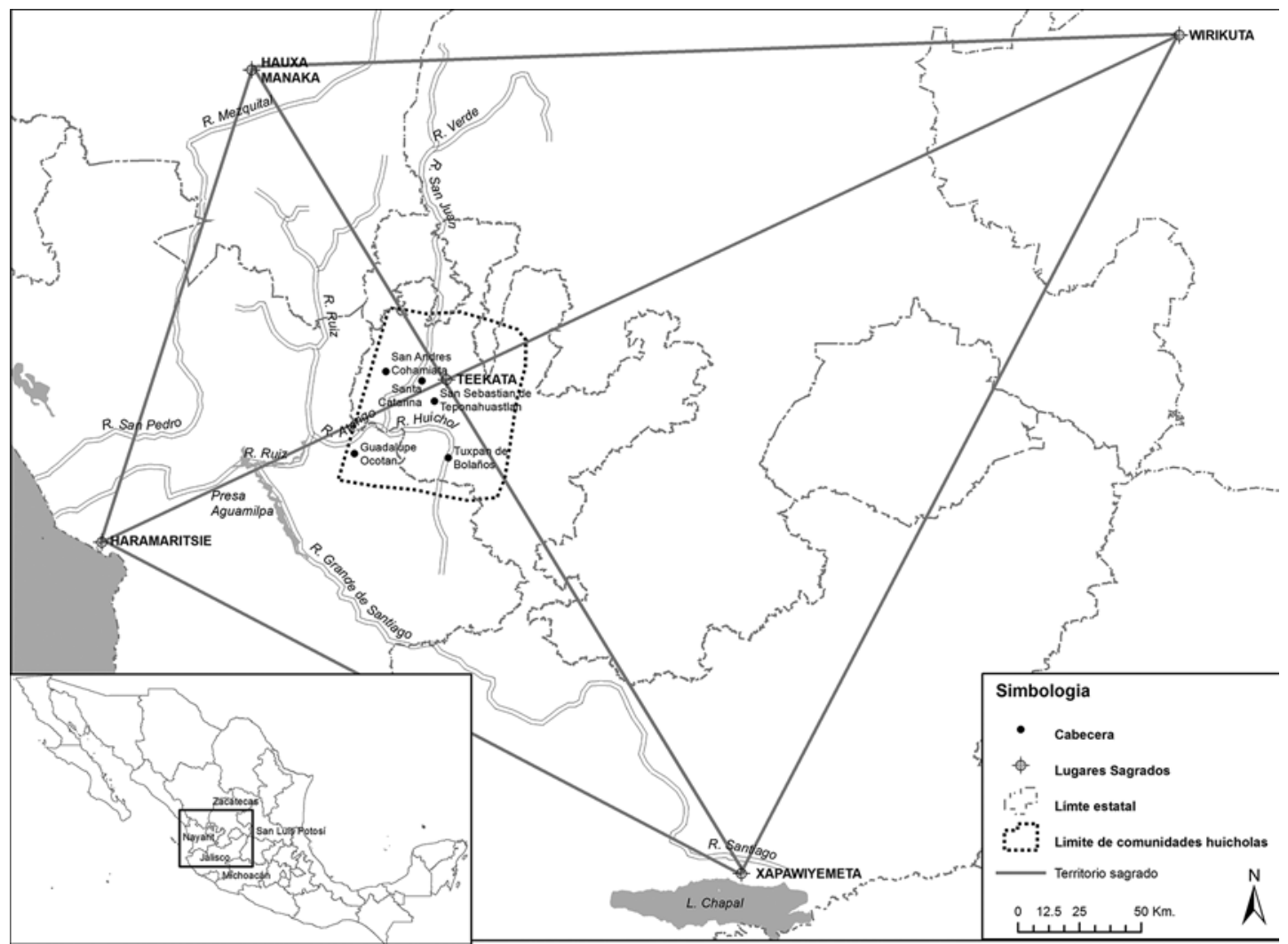

Mapa 1. El territorio Wixarika. Elaborado por Susan Alta Martin. Tomado del Journal of Southwest Vol. 42, $\mathrm{N}^{\circ} 1$. Verano del 2000. P: 130 .

de origen colonial en un contexto políticamente distinto (Rojas, 1992; Téllez, 2009).

Para William Roseberry, la importancia de la Historia, y su nexo con la Antropología, radica en su utilidad para comprender a las sociedades y los individuos en la actualidad (Roseberry, 1989, 1991). Bajo esta premisa, en Los campesinos y el mundo (1991), sostiene que la historia de las comunidades indígeno-campesinas es el resultado de una serie de transformaciones a lo largo del tiempo, basada en diferentes procesos. Una de las principales modificaciones al interior de estas comunidades es precisamente la reinterpretación de las jerarquías cívico-religiosas, cuyas principales transformaciones comenzaron en el siglo XIX y se acentuaron a lo largo del siglo XX (Chance y Taylor, 1985; Chance, 1990; Stephen y Dow, 1990). Al respecto, Weigand y García consideran que, en territorio huichol, las estructuras políticas más recientes se van incorporando a las ya existentes, sin eliminar nunca una forma previa, sino creando estratos organizacionales donde las estructuras más tradicionales se encontrarían en la base y las más nuevas en la parte superior (2000, 2002a).

De este modo, la base organizacional de las comunidades huicholas se encontraría en una institución de origen prehispánico caracterizada por la existencia de una jerarquía ceremonial que gira alrededor de los recintos tukipa (pl. tukite). Estos sirven como cabecera de distritos ceremoniales dominados por los kawiterutsixi y los xukuri'tkate o jicareros que, a la vez, cumplen con el papel de hikuri' 'tkate o recolectores de peyote ${ }^{1}$. La existencia de estos recintos refleja, en cierta medida, el modelo de organización territorial, social, política y ceremonial que prevaleció en la zona Nayarita y es evidencia de una serie de cacicazgos jerárquicamente organizados alrededor del recinto más importante de la región, al que rendían tributo periódicamente (Ortega, 1944, 1996; Weigand y García, 2000, 2002a; Téllez, 2006a, 2006b, 2009, 2010, 2011a, 2011b, 2011c).

Entre los siglos XVI y XVIII, los cronistas describieron la importancia del Templo del Sol 

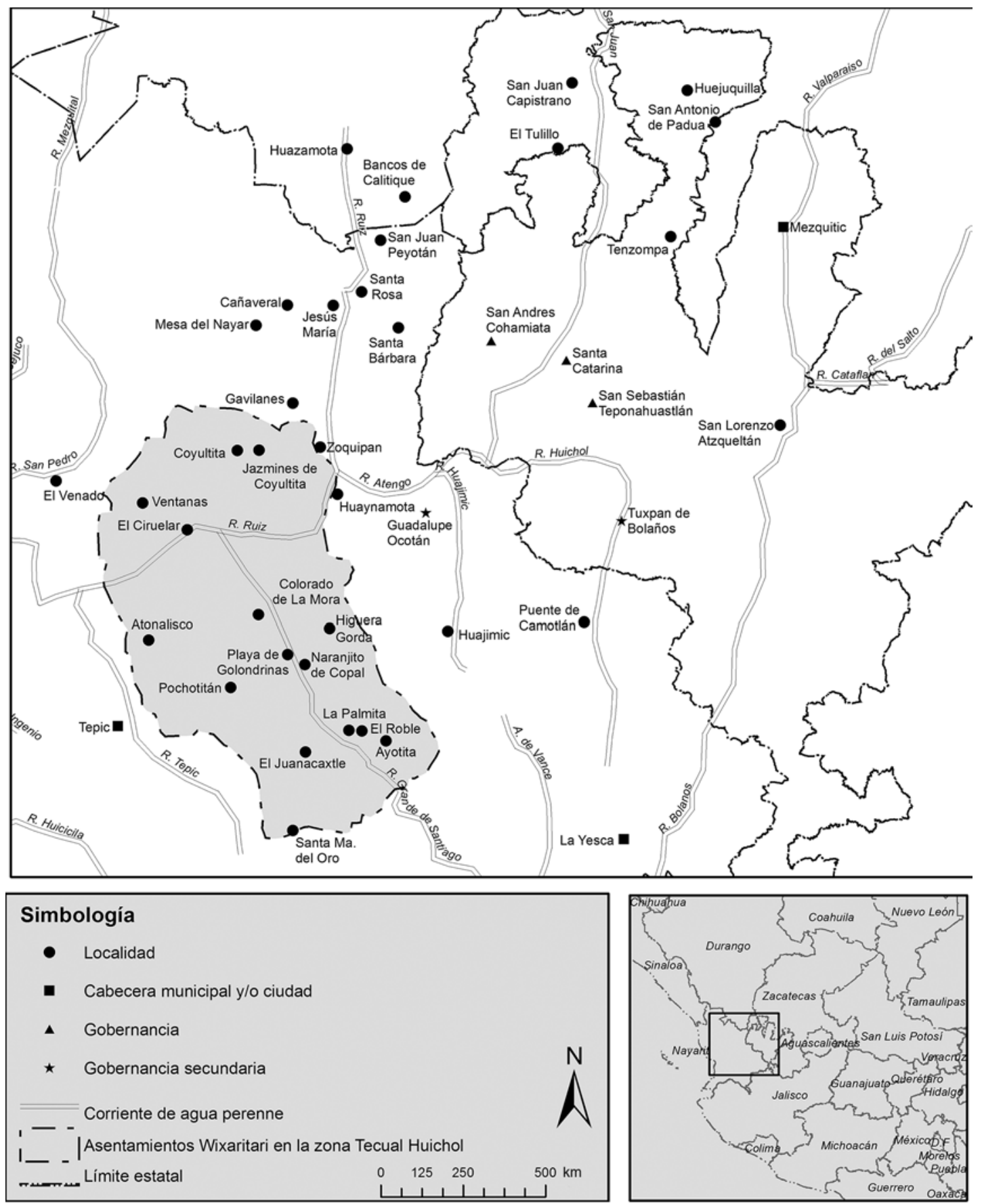

Mapa 2. Distribución de las comunidades huicholas y sus anexos, además de los asentamientos Wixaritari en la zona Tecual-huichol. Elaborado a partir de la carta estatal topográfica de Nayarit, escala 1:400 000 (INEGI, 2000).

ubicado en Tzacaimuta (Mesa del Nayar), el recinto ceremonial de mayor importancia en la zona Nayarita hasta la toma de este enclave en 1722 (Árias y Saavedra, 1975, 1986, 1990; Ortega, 1944, 1996). Esta información contrastada con el registro etnográfico nos pemite apreciar las continuidades, pero también las transformaciones en la realización de los mitotes o ceremonias (de carácter religioso, militar y agrícola), así como la entrega de tributos entre los distritos ceremoniales asociados a un 
templo particular. A su vez, esto nos da la pauta para comprender los cambios introducidos por los misioneros y las autoridades coloniales en la organización política y territorial de la zona Nayarita en general, y los huicholes en particular, a partir del siglo XVIII (Ortega, 1994, 1996; Weigand y García, 2000, 2002a; Téllez, 2006a, 2006b, 2009, 2010, 2011a, 2011b, 2011c).

Uno de los aspectos más interesantes en el análisis de las estructuras político-ceremoniales de los huicholes tiene que ver con la forma en que el conjunto de los kawiterutsixi, que dominaban los distritos ceremoniales de cada comunidad, mantuvo su importancia a pesar de la institución de las jerarquías civiles y religiosas de origen colonial. Esto se aprecia, especialmente, en el papel de estos personajes en la designación de los miembros de dichas jerarquías. Aunque hay referencias sobre esto en los documentos recuperados por Rojas (1992, 1993), las obras de Lumholtz (1986a, 1986b), Diguet (1992) y Preuss (1998), fue Robert Zingg quien describió de manera sistemática la importancia de los kawiterutsixi y los templos en la organización política, ceremonial y territorial de los huicholes (Zingg, 1982, 1998).

Sin embargo, autores como Vogt en 1955 (1972) y Dahlgren en 1962 (1972), así como Grimes y Hinton en 1969 (1972), ignoraban el papel de estos ancianos en la vida política de las comunidades y anotaban pocas referencias sobre los templos paganos (Dahlgren, 1972) o templos huicholes y los ancianos como cabezas de las familias extensas (Grimes y Hinton, 1972). Con ello se generalizó la idea de una estructura política igualitaria cuando, en realidad, nos encontramos con una organización muy cercana a lo que Carrasco denomina como un gobierno dual. Es decir, aquel que permitía que los antiguos grupos dominantes continuaran en el poder al mismo tiempo que se elegía a un grupo de funcionarios asociados al nuevo sistema político colonial (Carrasco, 1979: 334). En la zona Nayarita -y particularmente en territorio huichol- esta situación que se refleja en las fuentes etnohistóricas, pero también al registro etnográfico desarrollado desde finales del siglo XIX hasta la tercera década del siglo XX.

A finales de los años cincuenta, Fabila fue el único autor que documentó la importancia de los recintos tukipa, a los que menciona con el término genérico de calihuey (sic) ${ }^{2}$, como puntos focales de la vida ritual de los wixaritari $^{3}$. Además documentó el papel de los kawiterutisixi en la elección de los miembros de las jerarquías civiles de cada comunidad, sin llegar a comprender su importancia política y ceremonial en la estructura Tukipa. En este sentido, Fabila mencionaba a estos personajes como parte de un retirado relativo, explicando que: "con frecuencia las viejas autoridades civiles, agrarias y religiosas, tienen tanto prestigio, que (...) indican por sí quién o quiénes deben suceder a las que están en funciones, y el pueblo los confirma posteriormente" (Fabila 1959: 112).

Desde esta perspectiva igualitaria, pareciera que los kawiterutsixi eran individuos que habían obtenido algún nivel de prestigio por su participación en los sistemas de cargos de origen colonial, cuando en realidad formaban parte de una estructura de poder anterior. Esto puede entenderse porque Fabila no profundizó en el análisis de las fuentes, pero también porque su etnografía fue realizada a finales de los años cincuenta, época en que se hicieron evidentes las transformaciones introducidas por los movimientos armados regionales, las invasiones mestizas y la diáspora de la población huichola en diferentes direcciones (Weigand, 19924; Rojas, 1992; Téllez, 2011a, 2011c).

Phil Weigand, que desarrolló su investigación en la comunidad de San Sebastián Teponahuaxtlán a partir de los años sesenta, consideró diferentes aspectos para comprender la estructura política y ceremonial de los huicholes en esta época. Desde una perspectiva que conjugaba el registro arqueológico, etnohistórico y etnográfico, Weigand analizó cómo los movimientos armados que afectaron la región en los siglos XIX y XX, especialmente después de la Segunda Cristiada, modificaron los patrones de organización política y de diferenciación social de estas comunidades, así como las relaciones jerarquizadas entre cada distrito (Weigand, 1992) .

Durante este periodo, la destrucción del recinto ceremonial de Guadalupe Ocotán y la dispersión de su población introdujo modificaciones importantes al trasladar las funciones ceremoniales del recinto tukipa a la capilla. Cuando los misioneros tomaron el control de la misma, a mediados de los años cincuenta, las prácticas ceremoniales se trasladaron al recinto ceremonial de Witakwal La Mesa ${ }^{6}$ y, finalmente, a la Casa Real, lo que desembocó en la fusión de la estructura tukipa local con la cívico-religiosa (Téllez, 2006b, 2009, 2011a, 2011c).

De hecho, el colapso de la estructura tukipa en San Sebastián y Guadalupe Ocotán derivó en 
un fortalecimiento del sistema de cargos cívicoreligiosos a la vez que se acentuaron los rasgos asociados al modelo igualitario y redistributivo, descrito por Fabila, Hinton y Grimes y otros autores (Fabila, 1959; Hinton et al 1972). Con esto se modificaba radicalmente el panorama descrito por Zingg a mediados de los treinta (Zingg, 1982). Posteriormente, hacia los años setenta los procesos de reorganización comunitaria, posiblemente alentados por los ancianos cabeza de familia y los especialistas ceremoniales, debieron permitir la reorganización o reestructuración de la estructura tukipa tanto en Sebastián como en otras comunidades?

Esto pudo verse favorecido debido a dos aspectos: uno tendría que ver con la posibilidad de que las jerarquías tradicionales fueran reorganizadas y reforzadas ante la creación de nuevas formas de representación comunitaria que llegaron de la mano del indigenismo oficial mediante el Plan HUICOT (Huichol-Cora-Tepehuan). El segundo podría estar influido por los recursos económicos obtenidos por los artesanos que migraban a las ciudades que servían para patrocinar los festejos realizados alrededor de los adoratorios parentales, los tukite y las casas reales (Knab, 1981; Téllez, 2011a, 2011c). Sin embargo, algunas etnografías sostienen la continuidad de las estructuras ceremoniales (Neurath, 1998, 2002) o reproducen la idea de que los kawiterutsixi forman parte de la jerarquía cívico-religiosa (Vázquez Violante, 2010), más que pensar en la existencia de un oficio ceremonial asociado a los recintos tukipa. Interpretaciones como esta pasan por alto o disminuyen la importancia de los procesos históricos que afectaron la región y modificaron, e incluso pusieron en peligro, a las jerarquías tradicionales.

El segundo nivel, del que hablaré con mayor amplitud a lo largo de este trabajo, está compuesto por las autoridades civiles y religiosas instituidas durante el periodo colonial, representadas por los portadores de las varas de mando ('itsikame en singular, 'itsikate en plural) y los mayordomos, quienes se asientan en el pueblo principal, donde atienden la katsariana o Casa de gobierno y la capilla, respectivamente.

El tercer nivel lo integran las instituciones creadas por el Estado mexicano que sobreponen las instancias agrarias y municipales sobre las autoridades tradicionales. Este proceso, que se inició en el siglo XIX, trató de restar importancia a las jerarquías cívico-religiosas al instaurar un nuevo tipo de autoridad civil dependiente de los ayuntamientos de la región. En el plano agrario, desde mediados del siglo XX el Comisariado de bienes comunales y el Consejo de vigilancia son los encargados de la administración de las tierras y los recursos de la comunidad, además de gestionar los proyectos productivos y representar a la comunidad ante las instituciones oficiales. Este proceso no está exento de conflictos que deben ser debidamente analizados para comprender, cabalmente, la dinámica política de estas comunidades, debido a la competencia establecida entre diferentes familias para acceder a estos cargos y obtener algún grado de prestigio y poder que se reflejan en los aspectos políticos y económicos de la comunidad (Weigand, 19928; Durin, 2001; Torres Contreras, 2000; Téllez, 2005, 2011a, 2011b, 2011c).

A partir de lo anterior, este trabajo presenta un acercamiento histórico y antropológico sobre cómo las formas de gobierno local entre los huicholes se han visto modificadas a partir de la incorporación de nuevas estructuras políticas, impuestas sobre la estructura jerárquica nativa y la jerarquía cívicoreligiosa, aspecto que se liga con la discusión respecto de las formas de gobierno indígena en diferentes periodos y su relación con la formación y transformación del Estado posrevolucionario en México a lo largo del siglo XX. Este proceso adquiere matices particulares, debido a que los conflictos regionales y los constantes conflictos por los límites estatales, municipales y locales influyeron en la modificación de la estructura territorial, social, política y económica de esta comunidad.

\section{Antecedentes del gobierno tradicional Wixarika}

La organización política de las comunidades wixaritari contemporáneas (caracterizada por la presencia de un grupo de funcionarios encabezados por un gobernador) se basa en la estructura implantada dentro de los pueblos o repúblicas de indios, donde se instituyeron cabildos similares a los establecidos en los ayuntamientos españoles (Font, 1952; Carrasco, 1979; Lira y Muro, 2000). Aguirre Beltrán (1991a), Chance y Taylor (1985) y Chance (1990) han mencionado que en su origen el sistema de cargos tenía un sentido meramente civil, basado en una estructura jerárquica creada durante el periodo colonial para mantener un control políticoadministrativo sobre las comunidades indígenas y facilitar su explotación económica. A pesar de las 
modificaciones introducidas por este sistema, muchos elementos presentes en la estructura social, política y ceremonial preexistente subsitieron y, entre otras cosas, permitieron recanalizar las aspiraciones de los nobles indígenas para mantener su estatus al interior de las comunidades gracias a las normas establecidas por las leyes coloniales para la elección anual de autoridades indígenas (Carrasco, 1979; Chance y Taylor, 1985; Chance, 1990).

No obstante, la integración de estas estructuras jerarquizadas no estuvo exenta de fricciones entre los representantes de la antigua aristocracia indígena y la nueva organización administrativa que, en algunos casos, permitió que la designación y la elección de las autoridades recayeran directamente en los sujetos y barrios de la comunidad, lo que creaba una jerarquía específica en la representación comunitaria (Carrasco, 1979; Carmagnani, 1993). Un ejemplo de ello sucedió en 1572 con don Cristóbal, cacique y gobernador de Xalisco, Nayarit, quien vio amenazada su influencia cuando se establecieron los tequitlatos o fiscales apoyados por la Iglesia (Calvo, 1990).

La organización económica de las repúblicas de indios se basaba en la existencia de la comunidad, donde la tierra se convirtió en un patrimonio que debía ser preservado por la estructura jerárquica, integrada en un sistema de cargos, que a su vez era responsable de la administración de recursos, el trabajo y los gastos comunitarios (Carrasco, 1979; Carmagnani, 1993). Esto implicaba demarcaciones político-territoriales, dotadas con haciendas compuestas que eran reconocidas por la Corona española por medio de sus respectivos títulos (Lira y Muro, 2000; Weigand y García, 2000, 2002a), mecanismo que como Shadow hace notar, especialmente en el norte de Jalisco, fue instituido por las autoridades coloniales para salvaguardar los intereses de la Corona en tierras de potencial minero (Shadow, 1978, 2002). A su vez, los títulos coloniales que amparan la existencia de las repúblicas de indios se convierten en el fundamento legal de las comunidades indígenas contemporáneas ante las leyes agrarias (Liffman, 1996, 2011, 2012). Esta estructura comunitaria permitió que los territorios indios se organizaran bajo una lógica propia, resultado de una serie de interacciones demográficas, económicas, sociales, culturales, políticas y administrativas; lo que Carmagnani (1993) denomina como una lógica étnica.

A lo largo del siglo XVIII, la Corona española limitó las facultades dominicales de las comunidades indígenas, a las que se prohibió la enajenación de las tierras comunales sin el permiso de las autoridades. A su vez, se favorecieron las actividades de cultivo, con el fin de que las comunidades tuvieran la capacidad de pagar sus tributos correspondientes. De esta forma la estructura comunitaria se constituyó en el gobierno económico y la policía rural de los pueblos. Sin embargo, con el surgimiento del Estado borbónico se cuestionó esta estructura como una medida de carácter tutelar respecto de los indígenas (Meyer, 1984, 1986).

En cuanto a las asociaciones religiosas dedicadas a la organización y patrocinio del culto a los santos patrones, estas aparecieron entre los siglos XVII y XVIII y, en principio, existía una clara distinción entre esta jerarquía y la de carácter civil (Chance y Taylor, 1985; Chance, 1990; Lira y Muro, 2000). Como señalara Carmagnani (1993), la administración de los recursos de las comunidades adquiere con este proceso una doble connotación: por un lado, existían las cajas de la comunidad, destinadas a cubrir las necesidades materiales de la misma y, por el otro, las cofradías y hermandades se dedicaban a recabar los recursos necesarios para cubrir los gastos ligados a los rituales comunitarios.

Sin embargo, a partir de la segunda mitad del siglo XVIII comenzaron a fusionarse los sistemas civiles y religiosos de comunidades indígenas, como las de Oaxaca, en una sola estructura, proceso que se acentuó a lo largo del siglo XIX con las leyes de desamortización promovidas por los gobiernos liberales (Chance y Taylor, 1985; Chance 1990; Meyer, 1984, 1986). Esta adaptación del sistema de cargos fue una respuesta de las comunidades indígenas ante la expropiación de las posesiones de las cofradías - por parte de la Iglesia- y la prohibición del sostenimiento comunal de las fiestas religiosas por parte de los funcionarios coloniales (Chance y Taylor, 1985; Chance, 1990). Paradójicamente, estas instituciones creadas e impuestas por la administración colonial para asegurar el culto fueron utilizadas como una herramienta para esquivar la explotación colonial -por lo menos en Oaxaca-, de tal modo que en vez de instituirse en zonas de refugio de una etnicidad reprimida, se convirtieron en organizaciones relacionadas con la dinámica económica y social del territorio (Carmagnani, 1993).

No hay una referencia específica sobre la integración del sistema de cargos en la zona del río Chapalagana, pero Juan de la Torre, protagonista de la campaña de Nayarit, así como Ortega, indicaban 
la existencia de cargos civiles y militares en la primera década del siglo XVIII: "Don Andrés, capitán a guerra San Andrés Ocotán (Cohamiata) y su gobernador" y "Phelipe, gobernador y capitán a guerra Juan de la Torre”, de Santa Catarina ${ }^{9}$ (Juan de la Torre, citado por Rojas, 1992: 63; Ortega, 1944, 1996). A lo largo del siglo XVIII este modelo de organización se consolidó en Wautia/San Sebastián Teponahuaxtlan, Tuapurie/ Santa Catarina Cuexcomatitlan y Tateikie/ San Andrés Cohamiata, fundamento de las comunidades wixaritari contemporáneas, donde los sistemas de cargos civiles y religiosos se convirtieron en la base de lo que los huicholes reconocen como su gobierno tradicional y que era ratificado por las autoridades coloniales en Colotlán (Velázquez, 1961).

Esta estructura subsistió sin grandes cambios desde su constitución en el siglo XVIII, hasta las primeras décadas del siglo XX, aunque al igual que las estructuras previas, se ha adaptado en mayor o menor medida a los cambios político-administrativos de cada régimen. De hecho, hacia 1843, las autoridades huicholas seguían legitimando su posición ante las autoridades de Colotlán (Rojas, 1992: 149). Chance (1990) y Stephen (1990) han señalado que a partir del siglo XIX, y principalmente desde el periodo de la Reforma, los gobiernos estatales y nacionales procuraron reemplazar las estructuras coloniales de gobierno local por nuevos modelos acordes al proyecto nacional. Este proyecto político tuvo poca influencia sobre las comunidades indígenas de la región del río Chapalagana, por lo menos hasta mediados del siglo XX. Esto se debió principalmente a la lejanía y dispersión de sus asentamientos respecto de las capitales regionales mestizas, lo que les permitió mantener una relativa autonomía política para la organización interna de las comunidades y sus gobernancias.

A pesar de la relativa autonomía que gozaban, en la última década del siglo XIX las autoridades de Colotlán, por medio de la municipalidad de Mezquitic, tuvieron que definir el carácter y las atribuciones de las autoridades indígenas. Esto, en un periodo en que los gobernadores debían tomar medidas para proteger las comunidades de las invasiones promovidas por los mestizos de Huajimic y Camotlán, pero también ante los conflictos intercomunitarios, acentuados por la incertidumbre generada en cuanto a los límites entre Jalisco y el Territorio de Tepic. Por ello, en 1892, Sostenes Rodríguez, que fungía como autoridad política de
Mezquitic, indicaba que los gobernadores indígenas tenían el carácter de Comisarios de policía ${ }^{10}$, además de que enumeraba sus atribuciones y los límites de su jurisdicción debido a los conflictos que se suscitaron debido a los desacuerdos existentes por la delimitación territorial de cada comunidad, como se aprecia en esta carta enviada al gobernador de Tuxpan en 1892:

\begin{abstract}
"Los Gobernadores de Santa Catarina, San Sebastián, San Andres Cohamiata(,) Tuxpan, y Guadalupe Ocotan, no tienen más carácter que el de comisarios de policía, encargados de vigilar por la conservación del orden, de la seguridad y de la tranquilidad pública en su respectivo pueblo y tierras que les pertenecen, y en caso que dentro de los límites de dichas tierras se cometa algun delito contra las personas, como heridas u homicidios, ó contra la propiedad, como fraudes y robos, deben aprehender a los culpables y remitirlos a este Directorio.

Cada Gobernador debe limitarse al ejercer sus atribuciones, á la circunscripción de su pueblo, y con el carácter de agente de la autoridad, solo pasar a otro de prestar auxilio, o en caso de delito in fraganti, como el que se esta cometiendo o se acaba de cometer, y entonces los delincuentes que se aprehenda los entregara al gobernador o Comisario del pueblo en que lo haya aprehendido o los remitira directamente a esta Directoría, si fuese mas facil o expedito. Siendo de la misma categoría los Gobernadores o Comisarios, no debe uno librar órdenes de aprehencion contra otro si no en caso de delito in fraganti y en ningun caso puede uno castigar al otro, porque esta facultad la tiene solamente el Jefe Político del Cantón, los Directores de los Departamentos, los Presidentes municipales y los jueces de esta villa o los de Colotlán" (Carta dirigida al gobernador de Tuxpan por Sóstenes Rodríguez. Mezquitic. Junio 11 de 1892, en Rojas, 1992: 225-227).
\end{abstract}

Independientemente del término utilizado por los gobiernos liberales, los miembros del gobierno indígena huichol estaban facultados para mantener la paz e impartir justicia dentro de sus respectivas 
jurisdicciones. En este sentido, Lumholtz y Diguet indican que, a finales del siglo XIX y principios del XX, tanto coras como huicholes reconocían al gobierno mexicano y se sometían a sus disposiciones. En general, estas autoridades eran responsables ante el gobierno municipal de los delitos que se cometían dentro de su jurisdicción: impartían justicia y, cuando se trataba de crímenes mayores, tenían la responsabilidad de remitir a los culpables ante las autoridades de Colotlán (Diguet, 1992: 120; Zingg, 1982). Además, Lumholtz señalaba que el alcalde, el gobernador y el capitán, miembros de la estructura civil impuesta por los franciscanos, eran reconocidos por el gobierno de Jalisco como jueces.

$\mathrm{Al}$ mismo tiempo, las autoridades indígenas procuraron legalizar su existencia como representantes ante los ayuntamientos correspondientes, los que ratificaban estas designaciones mediante oficios firmados por los presidentes municipales y sus principales funcionarios, además de dotarlos del sello que permitía legalizar sus actos y los oficios enviados por las autoridades indígenas a instancias superiores. Por ello, cada año, antes de realizar la ceremonia del Cambio de vara, los funcionarios salientes llevaban a quienes los sustituirían hasta Colotlán para presentarlos ante las autoridades municipales como lo han apreciado autores como Lumholtz (1986a), Diguet (1992), Zingg (1982), Fabila (1959), Weigand (1992) ${ }^{11}$, Mata Torres (1970) y Anguiano (1974) en diferentes momentos.

En este contexto es evidente que la estructura jerárquica del gobierno indígena, que actualmente es reconocida como el gobierno tradicional wixarika, ha formado parte de un sistema político más amplio. Aunque el proyecto liberal intentó erradicar las formas de organización comunitaria ligadas al régimen colonial, podemos suponer que las condiciones geográficas y la influencia de Manuel Lozada, con su proyecto para preservar la estructura comunitaria en la zona Nayarita, limitaron esta aspiración (Meyer, 1984; Téllez, 2011c, 2011d). Por ello, en vez de erradicar los cargos de los gobernadores indígenas y su gabinete, fue más fácil dotar a esta estructura de un carácter oficial más apegado al sistema político nacional: los comisarios políticos o jueces.

En 1912, en el contexto de la lucha revolucionaria, el Congreso del estado de Jalisco erigió la Comisaría política y judicial de San Andrés Cohamiata con la idea de mantener, desde esta comunidad, el control de los pueblos o gobernancias que integraban a San Andrés, San Sebastián y Santa Catarina. Sin embargo, esto desató fricciones, ya que estas últimas se negaban a subordinarse a San Andrés Cohamiata. Además, es notable la resistencia que las autoridades indígenas manifestaron ante la creación de estas instancias. Al interior de la misma comunidad de San Andrés un personaje, de nombre Jesús Carrillo, levantó quejas contra los funcionarios encargados de la comisaría e, incluso, intentó apoderarse del sello que estaba a cargo de Francisco Martínez, comisario político, en 1913 (Rojas, 1992: 245-248).

Con la promulgación de la Constitución de 1917 se estableció un sistema que trató de reforzar la importancia de estos cargos políticos que competían con la importancia de la estructura tradicional. $\mathrm{Su}$ finalidad era sustituir estructuras políticas previas, limitar la autonomía de las comunidades indígeno-campesinas y fomentar la dependencia de las comunidades respecto del gobierno estatal y nacional. Este proyecto fue reforzado entre 1920 y 1940 por los gobiernos posrevolucionarios (Obregón, Calles y Cárdenas) bajo el concepto del Municipio Libre (Chance, 1990; Stephen, 1990).

Chance considera que el registro etnográfico disponible entre 1965 y 1986 nos permite apreciar cómo, a pesar de estas presiones, algunas comunidades lograron incorporar los nuevos cargos civiles dentro de su jerarquía cívico-religiosa de manera relativamente exitosa, aunque por lo general las estructura jerárquicas tradicionales vieron disminuida su importancia, convirtiéndose en sistemas de transición o sistemas religiosos. Esto generó, a su vez, la pérdida de autonomía de estas comunidades y el aumento de su dependencia respecto de los gobiernos estatal y nacional (Chance, 1990), como en la zona oriental del estado de Morelos (Warman, 1988).

En las comunidades wixaritari la existencia de estos comisarios ha persistido y han sido integrados dentro de la jerarquías comunitarias (Anguiano 1974, Neurath, 1998; Torres 2000; Escalante Carbajal 2010; Téllez, 2011c). Entre 1933 y 1934, Zingg pudo apreciar la presencia de un representante de este tipo en su descripción del cambio de varas en Tuxpan (Zingg, 1982, Tomo I: 137-138). A finales de los años cincuenta Fabila señalaba la existencia de los comisarios municipales en Santa Catarina, mismos que se encargaban de resguardar el orden en los ranchos, según su importancia (Fabila, 1959). A pesar del carácter civil de estos comisarios, Fabila 
señala que también eran elegidos por el pueblo y los kawiterutsixi entre septiembre y octubre (temporada que concuerda con la festividad de Yuimakwaxa o El Tambor) y que recibían su cargo del mismo modo que los funcionarios del gobierno tradicional (Fabila, 1959: 109).

A principios de los años setenta, Lühmann señalaba a estos funcionarios como el nexo entre las comunidades y las autoridades del país (Lühmann, 1971). Este cargo tenía un carácter meramente civil y, precisamente, esta era la categoría que recibían los gobernadores indígenas por parte de las autoridades mestizas. Hacia los años sesenta, en San Sebastián cada distrito Tukipa contaba con un comisario o delegado, mismo que representaba a cada distrito ante la cabecera de la comunidad o gobernancia. Debido a que se trata de jurisdicciones específicas, Weigand se refiere a estos distritos como /Tuki/ Comisario, ya que en el aspecto ceremonial estaban orientados hacia la jerarquía que atendía este recinto ${ }^{12}$, mientras que en el aspecto civil estos distritos estaban orientados hacia la figura del comisario o delegado, cargo de carácter civil asociado a la presidencia del Comisariado de bienes comunales en su calidad de líderes distritales, electivos o designados, aunque podían trabajar de acuerdo con los líderes tradicionales (Weigand, 1992) ${ }^{13}$. Escalante Carbajal indica que, en la actualidad, San Sebastián está organizada en dieciséis agencias municipales, incluyendo a la cabecera comunitaria. Cada una de ellas cuenta con un comisario primero y un comisario segundo o suplente, además de sus secretarios (Escalante Carbajal, 2010).

En Santa Catarina Neurath indica que cada uno de los tres distritos Tukipa que conforman esta comunidad cuenta con un comisario o representante del distrito ante el gobierno tradicional de la cabecera (Neurath, 1998: 146). Estos comisarios han sido integrados dentro de la jerarquía del Tukipa y cuentan con una oficina dentro del conjunto arquitectónico del centro ceremonial y, al interior del Tuki, existe un asiento reservado para él, pero no representan una autoridad suprema (Neurath, 1998: 170). A su vez, estos funcionarios tienen un grupo de representantes (agentes municipales o comisarios secundarios) responsables de las rancherías o agencias, subdivisiones políticas menores de la comunidad (Neurath, op cit.).

Mientras tanto, en San Andrés Cohamiata, Anguiano (1974) señala la existencia de seis comisarios (Pitahayas, San José, el Chalate, Las
Guayabas, Cohamiata, Huastita) como parte de la jerarquía civil, mientras que Kindl (2003) solo indica cuatro (San José, Cohamiata, Guayabas y Pitahayas $)^{14}$. En Guadalupe Ocotán existen dos comisarios plenamente integrados al gobierno tradicional, que también portan su respectiva vara de mando, además de que cuentan con un lugar en la mesa de las autoridades tradicionales. Además, en algunas rancherías, como Las Palomas, se elige también un comisario que asiste a las Asambleas comunitarias, las que se realizan el último domingo de cada mes, o cuando se es requerido en la cabecera de la gobernancia.

A pesar de la gradual introducción de nuevas instancias de autoridad civil, como los jueces de paz, auxiliares o delegados municipales, las comunidades wixaritari y sus anexos mantuvieron cierta autonomía respecto del gobierno municipal y estatal hasta mediados del siglo XX, gracias a la geografía de la región. Hasta entonces, el Gobernador indígena y su gabinete normaban la vida de la comunidad en casi todos sus aspectos: fungían como árbitro en disputas tales como los juicios por herencias, robos, brujería, adulterio, conflictos familiares, derechos por el uso de la tierra, etc. En el aspecto judicial, Fabila enfatizaba que la política al interior de las comunidades obedecía a patrones culturales propios e inalterables y autodeterministas, los cuales no eran objetados por las autoridades municipales y judiciales debido a que no interferían con las instituciones nacionales (Fabila, 1959). Es más, las autoridades tradicionales de estas comunidades continuaban legalizando su existencia ante los ayuntamientos respectivos, para que estos ratificaran las designaciones mediante oficios firmados por los presidentes municipales y sus principales funcionarios (Zingg, 1982; Fabila, 1959; Weigand, 1992 15; Mata Torres, 1970; Anguiano, 1974; Téllez, 2005, 2011c) (Imagen 1).

Al respecto convendría revisar los planteamientos de Fabila sobre la autodeterminación política de los pueblos indios, ejemplificados en sus etnografías sobre los yaquis $(1940,1978)$ y los huicholes (1959). En cuanto a los huicholes, Fabila propone que el reconocimiento del gobierno indígena por parte de los municipios de Mezquitic y de Bolaños implicaba el aceptar una personalidad jurídica inexistente en las leyes mexicanas, que no chocaba en absoluto con las instituciones nacionales y, al contrario, "debería estatuirse por justa y conveniente no solamente para ellos sino también para el país" (1959: 112-113). 


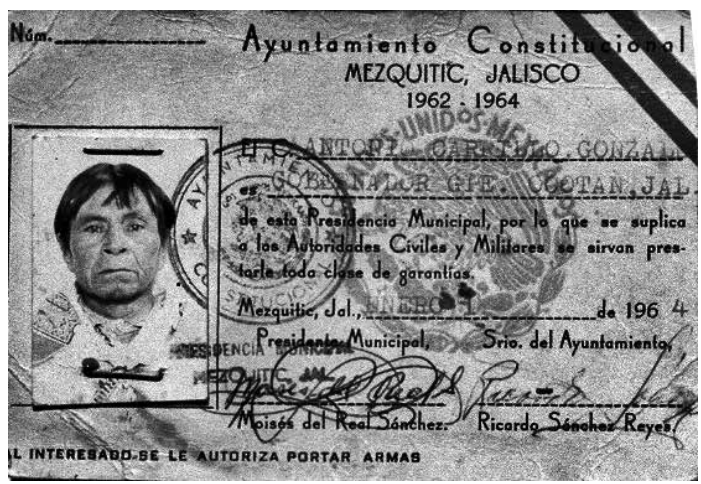

Foto 1. Credencial expedida por el ayuntamiento de Mezquitic, Jalisco, a Antonio Carrillo González, Tatuwani de Guadalupe Ocotán de 1964 a 1965.

\section{Características de la jerarquía cívico-religiosa entre los Wixaritari}

\section{Los 'itsikate o Portadores de la vara}

En términos generales, el sistema de cargos cívico-religiosos, establecido por los misioneros franciscanos en las comunidades huicholas, estaba conformado por un gobernador o tatuwani, un alcalde, un capitán de guerra y un alguacil real. Cada uno de estos funcionarios tenía un topil, excepto el capitán de guerra, que contaba con dos subordinados: un sargento mayor y un cabo (Lumholtz, 1986a; Rojas, 1992: 148-149, 210 y 225-227; Zingg, 1982). Estos funcionarios son sustituidos cada año y los ancianos o kawiterutsixi mantienen una gran influencia tanto en su elección como en sus decisiones. Todo este cuerpo de funcionarios civiles cuenta con un distintivo que les brinda autoridad al interior de la comunidad: las varas de mando, elaboradas con madera de palo de Brasil. Debido a que portan este distintivo en todo acto de carácter cívico o comunitario, este conjunto de funcionarios es llamado en lengua wixarika con el nombre de 'itsikate: portadores del bastón o vara de mando.

Tradicionalmente, la justicia era ejercida por el gobernador y su consejo por medio de audiencias en la casa de gobierno, donde estos funcionarios portaban las varas de mando correspondientes a su cargo. Entre los años treinta y sesenta los delitos más comunes en la región eran el robo, el atraco, el asesinato, el adulterio, las ofensas, las calumnias y los agravios sexuales contra las mujeres, además de la brujería y el abigeato (Zingg, 1982; Fabila, 1959; Weigand, 1992) ${ }^{16}$. Al respecto, Zingg señalaba que no existía ninguna distinción entre delitos públicos y privados y que la mayoría de las veces el gobierno indígena no imponía castigo alguno al acusado si se comprometía a indemnizar a los afectados. En cambio, los acusados de atraco y robo tenían que resarcir a la víctima por los daños, pagar honorarios a los funcionarios y ser recluidos en el cepo (Zingg, 1982), además de una serie de regaños y consejos por parte del gobernador y sus compañeros (Fabila, 1959). En tanto, los azotes son mencionados como un castigo ancestral que era aplicado, excepcionalmente, cuando no se pagaban los daños (Zingg, 1982).

No obstante, cuando había una situación de mayor trascendencia y las partes en disputa no estaban de acuerdo con la decisión del gobernador, este se reunía con sus auxiliares y los interesados para dictaminar un fallo, mientras que los delitos más graves -como el homicidio-eran turnados a las autoridades municipales de Mezquitic y Bolaños, donde se le dictaba sentencia al reo o era enviado ante las autoridades competentes, en Colotlán, Jalisco y los topiles-tupiri-eran los encargados de llevar a los presos ante las autoridades tradicionales o las constitucionales de los ayuntamientos (Fabila, 1959). Sin embargo, los mestizos que se encontraban dentro de territorio huichol desconocían a las autoridades indígenas, quienes a su vez evitaban involucrarse con ellos debido a su carácter agresivo y su costumbre de hacer gala de las armas que portaban. Por lo mismo, los delitos o faltas cometidos por los mestizos dentro de territorio huichol quedaban impunes (Fabila, 1959).

En general, el tatuwani o gobernador es el centro de la jerarquía civil y religiosa y, con ciertas restricciones, representa a su jurisdicción ante el ayuntamiento correspondiente. Sin embargo, en las últimas décadas los funcionarios de carácter municipal y agrario han absorbido muchas de sus atribuciones como intermediarios entre la gobernancia y el gobierno municipal y, también, en cuanto a su capacidad legal para administrar su territorio y negociar con las instituciones oficiales. Idealmente, el tatuwani tiene la capacidad de convocar y presidir las asambleas donde se resuelven asuntos relevantes para su respectiva gobernancia. Sin embargo, no puede decidir ningún asunto importante sin consultar con los otros miembros de la jerarquía civil y los kawiterutsixi, pero conserva la autoridad para ordenar la ejecución de los acuerdos tomados en asamblea e incluso puede anular las órdenes de otros funcionarios (Zingg, 1982). 
Según Weigand, solo este personaje puede anular el exilio dictado por sus antecesores. Los requisitos para acceder a este cargo son: el mantener una actitud tradicionalista, tener experiencia previa dentro del sistema de cargos, sin importar demasiado la edad; ser dedicado, confiable y respetable; tener cierto desahogo económico para poder afrontar los compromisos de su puesto, ser buen orador, buen escucha y tener buen juicio para solucionar los problemas que se le presenten, además de contar con buena salud. También es deseable su presencia para legalizar los contratos de compraventa de ganado. En el aspecto ritual el gobernador tradicional preside toda actividad del ciclo ritual, además de que puede ser invitado especial en los festejos familiares de las rancherías (Weigand, 1992) ${ }^{17}$.

El juez o alcalde (arkarite), quien se sienta a la derecha del gobernador, tiene la capacidad para intervenir activamente en los asuntos no judiciales de la comunidad, aunque en ausencia del gobernador puede actuar en su representación (Zingg, op cit.). En Guadalupe Ocotán este personaje es también conocido como segundo gobernador. Por su parte, Weigand señala que es a esta autoridad a la que se presentan las solicitudes para tener audiencia ante el gobierno tradicional y realizar un juicio (Weigand, 1992) ${ }^{18}$. Por otro lado, el capitán originalmente era un cargo de carácter militar (conocido como capitán de guerra), aunque ya en el siglo XX Zingg lo catalogaba como responsable de la fuerza policial del gobernador, además de que podía emitir su opinión en los asuntos comunitarios (Zingg, 1982). En tanto, el alguacil (arkwatsine) es el encargado de ejecutar las sentencias emitidas por los funcionarios reunidos en consejo y dictadas por el gobernador. Como se verá más adelante, este cuerpo de gobierno civil puede tener algunas variaciones, tanto en su orden como en su número. Ejemplo de ello es que Zingg (op cit.) describe que en Tuxpan el capitán era quien se responsabilizaba directamente de los topiles, mientras que Weigand $(1992)^{19}$ señala que esta obligación recae en el alguacil. Cada uno de estos funcionarios a su vez cuenta con un topil (tupiri) o ayudante, quienes sirven a su vez como policías y mensajeros de la comunidad. Aunque están bajo el mando directo del alguacil -o el capitán, según el caso- pueden recibir órdenes directas del gobernador tradicional (Weigand, 199220; Zingg, 1982).

Los topiles generalmente son personas jóvenes en quienes recaen los trabajos más pesados (cacería, levantar ramadas, participar en el trabajo comunitario, recorrer grandes distancias para hacer arrestos o llevar mensajes) durante un periodo de prueba que sirve para detectar el posible potencial para acceder a un cargo principal en el futuro (Weigand, 1992).

Zingg fue el primer antropólogo en analizar detenidamente la organización del sistema de cargos cívico-religiosos, además de contrastar su información con la de otros autores, lo que le permitió percibir las variaciones existentes respecto de las jerarquías cívico-religiosas de Tuxpan, San Andrés y San Sebastián (Zingg, 1982). De este modo realizó valiosas descripciones de las funciones rituales y civiles del gobierno tradicional huichol, lo que le permitió reconocer la influencia de las prácticas religiosas introducidas por los franciscanos en las ceremonias encabezadas por este cuerpo de gobierno. Este autor fue el primero en registrar la importancia política de los kawiterutsixi sobre la jerarquía tradicional al indicar que estos personajes eran los encargados de elegir a los nuevos funcionarios de Tuxpan, en un proceso ceremonial que iniciaba desde octubre. Este iniciaba con una ceremonia en la Casa Real o Casa de gobierno, donde cada kawiteru recibía una botella de licor (mezcal o sotol) de cada uno de los miembros del gobierno indígena (Zingg, 1982; Anguiano, 1974; Téllez, 2011c).

Durante las tres noches siguientes, los kawiterutsixi velaban mientras entonaban el ciclo mítico cristiano, a la vez que bebían el licor recibido de cada uno de los funcionarios con la intención de volverse lo suficientemente sagrados como para poder soñar a quienes integrarán el nuevo gabinete. Zingg indica que "una vez que han discutido sus sueños, aconsejan a aquellos que han elegido" y, posteriormente, en noviembre, se realizaba otra reunión en la Casa Real, donde los kawiterutsixi dedicaban a los nuevos funcionarios civiles y religiosos un discurso, que duraba de dos a tres horas, en que los instruían en todo lo referente a sus obligaciones (Zingg 1982, Tomo I: 111). Finalmente, entre diciembre y enero, durante la ceremonia del Cambio de Varas, los kawiterutsixi realizaban las ceremonias correspondientes para que los funcionarios salientes entregaran las varas de mando a sus sucesores ${ }^{21}$.

En Guadalupe Ocotán este proceso se realiza a lo largo de tres ceremonias: Hiwatsixa o Las Últimas, cuando inicia la temporada de lluvias y se clausuran temporalmente las actividades 
del Kaliwei/ Casa de gobierno; Yuimakwaxa o el Tambor, festejo que se realiza entre septiembre y octubre, cuando se recogen los primeros frutos de los coamiles y se reestablecen las funciones del gobierno indígena y, finalmente, durante el cambio de varas, cuando se relevan las autoridades de esta gobernancia. Hiwatsixa y Yuimakwaxa se realizaban originalmente en el recinto tukipa de Xatsitsarie, ceremonias que después se repetían en los ranchos de esta gobernancia. Sin embargo, estos festejos fueron trasladados la Casa de gobierno y, ante la desaparición de la jerarquía de los xukuri'ukate, fueron fusionadas con la elección de los miembros de la jerarquía cívico-religiosa, además de que son realizadas bajo la responsabilidad del tatuwani y su gabinete. El licor, tabaco y una vela, entregadas por cada funcionario al kawiteru de Guadalupe Ocotán durante la fiesta de Hiwatsixa, son dones que conectan las intenciones de los 'itsikate, el kawiteru y los mara'akate, con los que se puede compartir estos dones, para soñar y ubicar a las personas indicadas para sustituir a cada miembro de la jerarquía cívico-religiosa de esta gobernancia.

Aunque esta estructura jerárquica mantiene un patrón general en su organización, existen ciertas variaciones que se hacen evidentes en cada una de las cinco gobernancias contemporáneas, como se aprecia en el Cuadro 1. En él presento la información vertida por varios autores bajo dos criterios: por gobernancia y por el año en que se obtuvieron o publicaron estos datos. Debe señalarse que el orden en que aparecen funcionarios es el mismo que aparece en los textos revisados. La primera columna se basa en la información de un documento eclesiástico, fechado en 1843. Dicho documento narra la visita realizada por los miembros del Colegio de Guadalupe para conocer la situación en que se encontraba la misión de San Sebastián (citado en Rojas, 1992: 148-149). Aunque esta visita incluyó a Santa Catarina y San Andrés, es muy probable que esta estructura jerárquica corresponda a San Sebastián, debido a la similitud con los datos aportados por Klineberg, presentes en la segunda columna (Klineberg, 1934, 1972).

En cuanto al sargento y al cabo, que son señalados como ministros o topiles del capitán a guerra en la primera columna, Klineberg proponía que la existencia de estos funcionarios subalternos en San Sebastián implica una fuerte penetración de la nomenclatura gubernamental española en esta comunidad. Además, en la lista de Klineberg, existe un alguareal, que es catalogado asistente o topil del alguacil, aunque su nombre parece derivar de la denominación de alguacil real, presente en la primera columna. En cambio, Fabila, en la tercera columna, parece haber apreciado al alcalde o juez como dos funcionarios distintos. El Mayor que pone a continuación del capitán, bien podría ser el sargento mayor anotado en la segunda columna, mismo que desaparece en la cuarta. Después de este funcionario solo menciona a un secretario y los topiles. Entre 1966 y 1969 Weigand (cuarta columna) indicaba que el sistema de cargos de esta comunidad estaba integrado por un gobernador, juez, capitán y alguacil con sus respectivos topiles (bajo el mando directo del alguacil), además de un suplente para el gobernador (Weigand, 1992) ${ }^{22}$. Hacia la última década del siglo XX, Escalante Carbajal (2010) marca una configuración similar, aunque anota también a un secretario ${ }^{23}$. A estos suma dieciséis comisarios, mientras que Weigand solo se refería a tres, aspecto que debe ser revisado aún (quinta columna).

En Tuxpan de Bolaños, Zingg y Fabila (columnas seis y siete) concuerdan en cinco de los cargos, aunque hay una variación en el orden de los mismos en cuanto al capitán y el alguacil. Sin embargo, Zingg detalla la existencia del fiscal, cargo que recayó en un kawiteru durante la época del Carnaval (Pachitas), y en la Tenanche, sin incluir al sargento, mencionado por Fabila en la columna siete. Mientras tanto, en Santa Catarina -columnas ocho, nueve y diez- presentan datos similares en lo fundamental, aunque varía el orden de aparición del alguacil y el capitán en la columna nueve.

Respecto de San Andrés Cohamiata, aparecen los datos proporcionados por Beals a Zingg, los de Anguiano (1974), Arcos (1998) y Kindl (2003) en las columnas once, doce, trece y catorce. El primero, solo indica tres cargos: Gobernador, Juez y Fiscal. El cargo de sargento solo aparece señalado por Anguiano en la columna doce. Un aspecto interesante en las columnas doce y trece es la inclusión de los secretarios dentro del sistema de cargos de San Andrés, además de la columna quince, que corresponde en Guadalupe Ocotán. En el pasado el puesto del secretario no se encontraba dentro de las jerarquías tradicionales debido a que generalmente era ejercido por individuos medianamente ilustrados y, la mayoría de las veces, por mestizos (Rojas, 1992; Téllez, 2011c). Otra novedad, aparte del secretario es el cargo de tesorero en la columna 


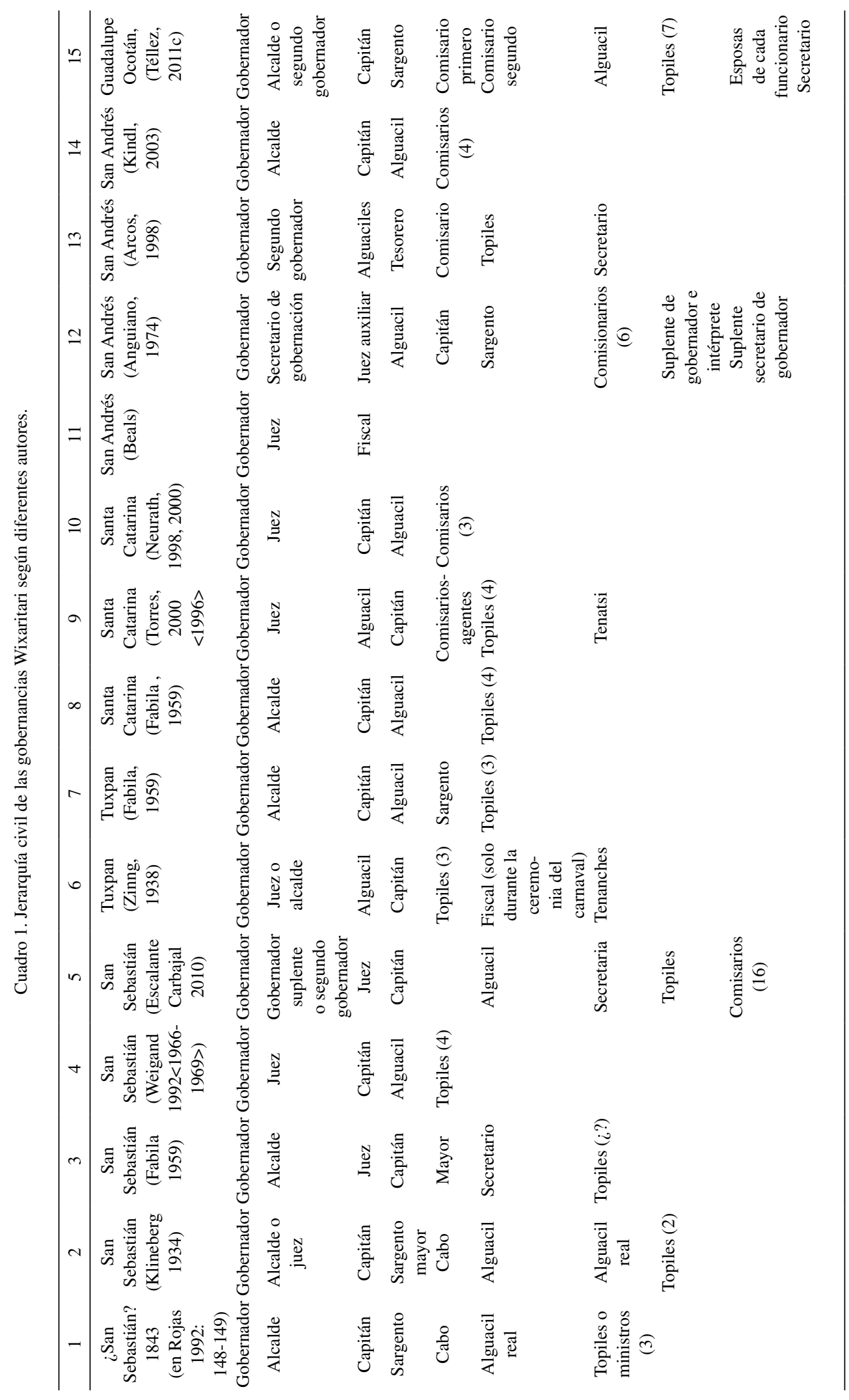


trece, cargos que no son contemplados por Kindl. En cuanto a los alguaciles señalados por Arcos en la columna trece, es posible que esta pluralización se refiera tanto al capitán como al alguacil, señalado por Kindl en la columna catorce.

Un elemento notable en este cuadro es que los términos de juez, segundo gobernador y alcalde parecen corresponder a un mismo funcionario, debido a las similitudes entre estos términos en la mayoría de las columnas, salvo en la número doce, donde se menciona un juez auxiliar y un suplente de gobernador. Por último, la columna quince corresponde a la información recabada en Guadalupe Ocotán (Téllez, 2001, 2005, 2011c). En esta gobernancia el Arkarite o alcalde es designado de forma explícita como segundo gobernador. En esta última se ha integrado, muy recientemente a la jerarquía tradicional el cargo de secretario, introducido por un maestro que vivió algún tiempo en San Andrés, cuando asumió el cargo de gobernador tradicional en 2006. En este último ejemplo, la lista de cargos se basó en dos criterios: el orden en que cada funcionario es acomodado en la mesa de autoridades, así como el orden que llevan en las procesiones previas al cambio de varas y otras actividades comunitarias.

\section{Algunas particularidades de la jerarquía cívico-religiosa de Guadalupe Ocotán}

La jerarquía cívico-religiosa de Guadalupe Ocotán fue instituida tardíamente en el siglo XIX (Rojas, 1992, 1993; Téllez, 2009, 2011a, 2011c). En la actualidad está integrada por la estructura civil constituida por los 'itsikate, y la religiosa conformada por los mayordomos o mariatumatsixi y sus ayudantes. En el pasado, ambas estructuras ocupaban dos espacios distintos: las autoridades civiles, encabezadas por el tatuwani, atendían los asuntos relacionados con la administración civil de la gobernancia en la Casa real o Casa de gobierno (katsariana), además de que presidían las principales celebraciones religiosas del año, como la Semana Santa. En tanto, la capilla era atendida por los mayordomos o mariatumatsixi, encargados de las imágenes de la Virgen y del Santo Cristo, organizar los festejos religiosos ligados al culto católico, la administración de ofrendas y cuidado de sus reliquias. Además, entre los años treinta y cincuenta del siglo XX, la capilla había absorbido el carácter ceremonial del tukipa, y en ella se realizaban las ceremonias de Hiwatsixa o Las Últimas y Yuimakwaxa o El Tambor.

Cuando los misioneros retomaron sus actividades en la zona, prohibieron la realización de ceremonias relacionadas con el recinto tukipa al interior de la capilla, pero también limitaron las actividades de los mayordomos. En un principio, las ceremonias tradicionales se trasladaron por un tiempo al recinto ceremonial de Witakwa/ La Mesa. Finalmente, este proceso favoreció la integración de la jerarquía civil y la religiosa en un solo espacio: la Casa de gobierno, sede de la administración civil de esta gobernancia, que tuvo que adaptarse para cumplir con el ciclo ceremonial católico. Para ello, las autoridades indígenas se vieron obligadas a conseguir una nueva imagen de la Guadalupana, que se encuentra en el interior del kaliwei/ Casa de gobierno ${ }^{24}$. A la vez se estableció un largo proceso de negociación con los misioneros para que permitieran que las imágenes de la Virgen y al Santo Cristo fueran atendidas por la jerarquía cívico-religiosa, por lo menos en las principales ceremonias que se realizan en este recinto, además de dejarle ofrendas en la capilla al finalizar las fiestas. De esta manera, el tatuwani y su gabinete, junto a los mayordomos, son responsables del ciclo ceremonial integrado por festejos como el Cambio de varas, Pachitas o Semana Santa.

Con el tiempo la Casa real adquirió una nueva connotación: con la desaparición del tuki y la estructura que permitía su subsistencia, este recinto y la jerarquía cívico-religiosa se convirtieron en una representación de la comunidad y su territorio. Los'itsikate representan a las familias de esta gobernancia y son los encargados de cumplir con el ciclo ceremonial, que incluye las fiestas de Hiwatsixa y Yuimakwaxa, que contribuye a propiciar la reproducción de la comunidad y sus habitantes. Posiblemente, ante esta fusión, la Casa real obtuvo la categoría de kaliwei, la designación de origen náhuatl que designaba indistintamente a los templos y adoratorios durante el siglo XIX. Así, el kaliwei/Casa de gobierno es el resumen de los tres principales espacios político-ceremoniales comunitarios: el tukipa, la Casa Real o Casa de gobierno y la capilla. Esta situación no es exclusiva de Guadalupe Ocotán, pues en los años treinta Zingg indicaba que la Casa Real de Tuxpan de Bolaños, además de centro político de esta gobernancia, cumplía también con las funciones de recinto tukipa y capilla católica, de tal modo que 
también contaba con el pozo destinado a recibir las ofrendas realizadas en cada ceremonia (Zingg, 1982, Tomo I: 357) ${ }^{25}$. Esta situación, igual que en Guadalupe Ocotán, obedece a procesos históricos particulares: al parecer en Tuxpan, zona ocupada por los refugiados de Ostoc, no existía un recinto tukipa y, además, nunca se concluyó la construcción de la capilla, tal como lo señala Zingg (1982, Tomo I). En cambio, en Guadalupe Ocotán esta simbiosis se originó a partir de la tercera década del siglo XX (Téllez, 2006b, 2009, 2011a, 2011b, 2011c).

\section{Los ‘itsikate de Guadalupe Ocotán}

En conjunto, el cuerpo civil de la jerarquía cívico-religiosa de Guadalupe Ocotán está integrado por el tatuwani o gobernador, el arkarite, alcalde o segundo gobernador; el kapitani o capitán, el tsaraketi o sargento, dos comisarios: primero y segundo y el hariwatsini o alguacil. De ellos, los comisarios, teóricamente, deben representar a las principales rancherías de la gobernancia, aunque también pueden desempeñar este cargo gentes del pueblo principal. Casi todos estos funcionarios ocupan un lugar en la mesa de las autoridades, salvo el hariwatsini. Frente a la mesa de las autoridades existe un tronco que sirve como asiento de este último y los tupiritsixi. Estos sirven como ayudantes de cada uno de los funcionarios, además de que cumplen con la función de policías y emisarios cuando es necesario. Aunque son ayudantes de un funcionario específico, el $h a$ riwatsini tiene la autoridad suficiente para darles órdenes, siempre y cuando exista una comisión aprobada por el tatuwani y el resto del gabinete. La jerarquización de estos cargos se representa en el siguiente cuadro (Cuadro 2).

Cuadro 2. Distribución de los 'itsikate en la escala jerárquica de Guadalupe Ocotán (Integrado al texto).

Kawiteru
Mara'akame
Mesa principal:
-Tatuwani o Primer gobernador
-Arkarite, Alcalde o Segundo gobernador
-Kapitani o Capitán
-Tsraketi o Sargento
$\quad$-Primer comisario
$\quad$-Segundo comisario
Asiento inferior
- Hariwatsini o Alguacil
$\quad$-Tupiritsixi o topilillos (7)

Si bien esta jerarquía cuenta con siete funcionarios principales y sus respectivos topilillos, lo que nos da un total de catorce miembros, es necesario que cada uno de estos funcionarios tenga una compañera, que generalmente es su esposa, por lo que la suma de todos asciende a veintiocho miembros del gabinete. Al respecto, Lumholtz señalaba la existencia de las tenantsi o tenanches, mujeres dedicadas a cumplir con ciertas labores de carácter doméstico para los funcionarios civiles y religiosos (Lumholtz, 1986a, Tomo II: 243, 244).

En realidad, las mujeres juegan un papel de gran importancia en cualquiera de las jerarquías tradicionales, ya sea en el recinto Tukipa, la Katsarianal Casa de gobierno o las capillas (Imagen 2). En cualquiera de las jerarquías asociadas a estos recintos es un requisito indispensable que todo funcionario tenga una compañera que comparte el prestigio, las obligaciones y el respeto que acompaña al cargo de su esposo (Weigand, 1992) ${ }^{26}$. Por ello, las mujeres de los funcionarios principales tienen mando sobre las esposas de sus respectivos topiles, que les ayudan

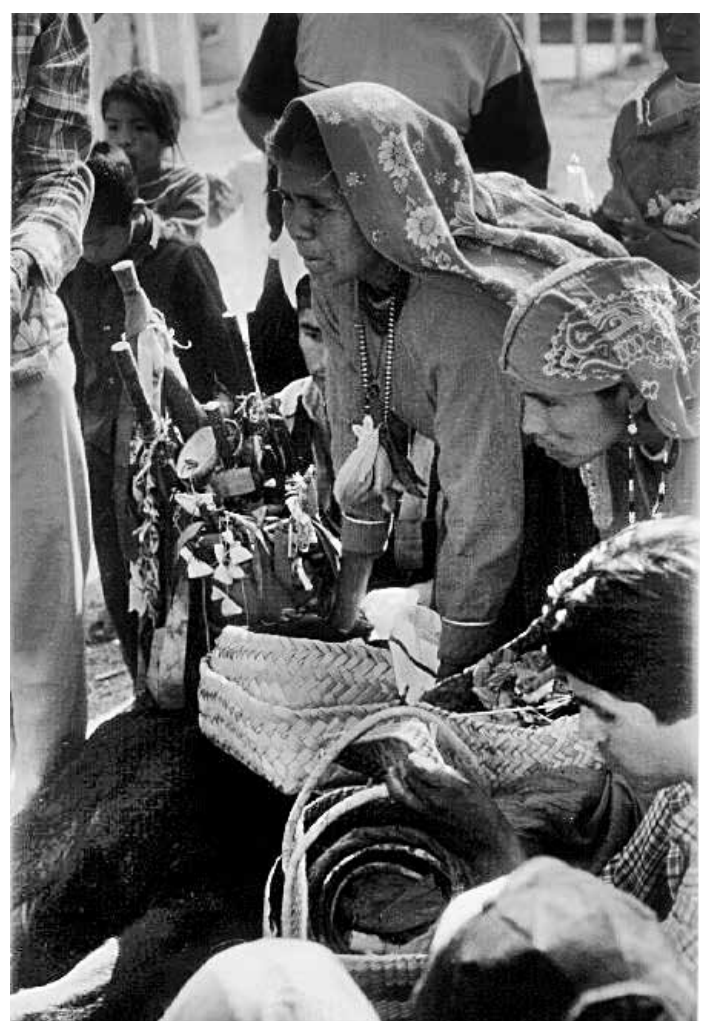

Foto 2. Funcionarios de la jerarquía cívico-religiosa portan las varas de mando y las reliquias de los santos durante la celebración de la Semana Santa de 2001. 
a preparar los alimentos (tejuino, atoles, tamales, tortillas y otros alimentos) que serán compartidos en cada ceremonia. Además, acompañan a sus maridos durante las mismas y portan los alimentos que, junto a otra parafernalia, adquieren un carácter sagrado. $\mathrm{Su}$ importancia es tal que, cuando un hombre es postulado por un cargo importante y es viudo, debe ser acompañado por su madre u otra mujer de la familia que represente el complemento femenino para este cargo. En otras situaciones, un hombre puede negarse a aceptar un cargo si su esposa se niega a acompañarlo en estas responsabilidades.

\section{Las varas de mando}

Cada uno de estos funcionarios cuenta con una vara de mando, todas del mismo tamaño y grosor aproximado, adornadas con casquillos de bala y listones que portan cuando atienden alguna diligencia, asisten a las Asambleas comunitarias, convocan a alguna reunión en el kaliwei/ Casa de gobierno o durante los festejos asociados a este recinto. Estas varas son de uso cotidiano y generalmente se portan en la cintura o en el morral. En el interior del $\mathrm{ka}$ liwei, frente a la imagen de Tanana/ Guadalupe, se resguardan unas varas de mando de mayor tamaño y grosor, adornadas con gruesas cintas de colores en su extremo superior, que corresponden a los funcionarios principales y su tamaño determina, jerárquicamente, el cargo que representa. Cada una de estas varas está envuelta en una serie de paños de colores que se van acumulando año con año y que representa a cada uno de los funcionarios que la ha portado. Estos paños, además de la vara, envuelven una serie de ofrendas, como flechas ceremoniales, velas, un pedazo de mecate o lazo, monedas y plumas. Durante algunas fiestas, como el Cambio de Varas, el extremo superior de estos bastones es adornado con una guirnalda de pequeñas tortillas o figuras de maíz. Durante esa ceremonia y la Semana Santa el conjunto de estas varas de mando es amarrado con un lazo y el alguacil, ayudado por los topiles o algún otro funcionario, se encarga de portar este bulto en las procesiones (Imagen 3).

\section{Los mariatumatsixi o mayordomos}

A la par de las autoridades civiles de la comunidad, se encuentran las autoridades religiosas, que se ocupan de los asuntos referentes al culto de los santos en sus respectivas capillas y que se ligan a los funcionarios

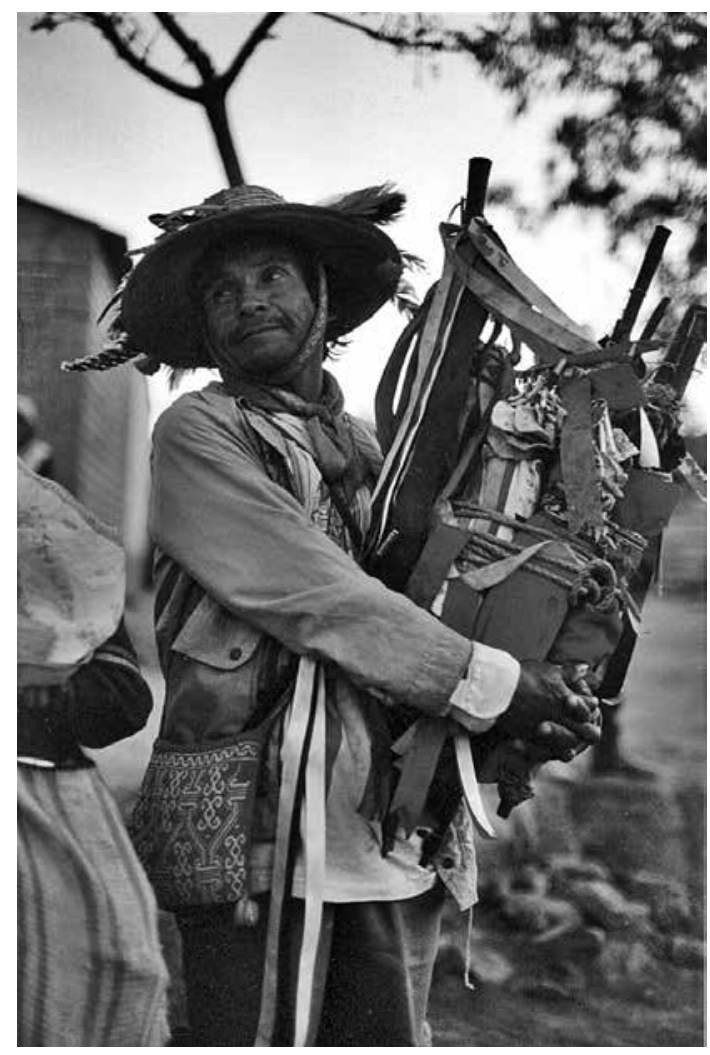

Foto 3. Funcionario portando las varas de mando durante el cambio de varas del 2001.

civiles tradicionales en las ceremonias comunitarias. A pesar de su importancia en el ámbito comunitario, las mayordomías han recibido menor atención por la etnografía contemporánea, que ha prestado mayor atención a las fiestas del ciclo católico y su relación con el culto solar de origen prehispánico, así como a la parafernalia asociada (Neurath, 2002; Lemaistre y Kindl, 1999; Kindl, 2003).

La mayoría de los documentos producidos entre los siglos XVIII y XIX no hacen ninguna alusión sobre la existencia de los mayordomos dentro de las comunidades huicholas. Al parecer, las primeras referencias sobre ellos aparecen en un informe misionero realizado, al parecer, a mediados del siglo XIX (Herrera Guevara, 2013) ${ }^{27}$ y en el texto enviado por Rosendo Corona a Santoscoy en 1888 (Santoscoy, 1986: 951; también citado en Rojas, 1992: 210) y Lumholtz (1986a). Sin embargo, es posible que la primera jerarquía religiosa en esta región fuera instituida en San Sebastián de manera simultánea o levemente posterior a la fundación de la misión, entre 1727 y 1733, para atender la capilla (Gerhard, 1996; Campos, 1979; Rojas, 1992). Para 
esta época comenzaron a fusionarse los sistemas civiles y religiosos de comunidades indígenas de Oaxaca, proceso que se acentuó durante el siglo XIX con las leyes de desamortización promovidas por los gobiernos liberales (Chance y Taylor, 1985; Chance, 1990; Meyer; 1984, 1986). Este proceso no se dio en las comunidades Wixaritari. De hecho, la única fusión de los sistemas de cargos civiles y religiosos se dio en Guadalupe Ocotán, hasta mediados del siglo XX (Téllez, 2011c).

En general, existe una separación bien definida entre la jerarquía tradicional asociada a los recintos tukipa, el gobierno indígena asociado al kaliwei/ Casa de gobierno y los mayordomos con el teyeupani/Capilla católica. En cuanto a las estructuras de origen colonial, esta jerarquía de carácter religioso es la que presenta más variaciones, debido a que cada comunidad cuenta con un número distinto de mayordomos. Los mayordomos pueden definirse como los custodios de los santos y guardianes de las reliquias sagradas relacionadas con ellos, cuyo número varía según el número de imágenes que haya en cada iglesia (Lumholtz, 1986a; Weigand, 1992). Lumholtz señala que en Santa Catarina había dos crucifijos y cuatro santos: la Virgen de Guadalupe, San José, Santa Catalina y San Antonio. Cada una de estas imágenes estaba a cargo de un mayordomo obligado a cuidar el dinero (y las ofrendas) que recibía cada santo (Lumholtz 1986a, Tomo II: 186). Otros funcionarios asociados a estos cargos eran los alguaciles y cuatro priostes o ejecutores que servían como ayudantes de los mayordomos. Además menciona ocho mujeres o tenanchas que se encargaban de mantener limpia la iglesia, atender a los santos y preparar alimentos durante las fiestas. Cinco de ellas estaban asignadas también a las casas de los mayordomos para ayudar a sus esposas en sus labores domésticas (Lumholtz, 1986a, Tomo II: 244) ${ }^{28}$.

Lumholtz menciona que durante su estancia en Santa Catarina, en las celebraciones previas a la Navidad y el Cambio de Varas, se realizaba la danza de los matachines en la capilla y se encendían cohetes. Asimismo, las imágenes religiosas eran adornadas con plumas, bolsas, cascabeles, soguillas de cuentas, etc. Además una limosna u ofrenda especial eran las monedas de plata que, colgadas en cintas rojas, adornaban los cuadros. Estas ofrendas eran indispensables al finalizar las fiestas que se realizan en los ranchos para realizar peticiones de salud, lluvias o para poseer más ganado. Para ello, en la actualidad aún se solicita al mayordomo encargado de algún santo en particular que lleve la imagen al rancho en que se realizará la fiesta, donde el mara'akame realiza el canto, se baila y se sacrifica la vaca, sin olvidar colocar la limosna en las cintas (Lumholtz, 1986a, Tomo II: 186).

Cuando se realizan estas ceremonias, los mayordomos tienen la obligación de montar un altar adecuado para la imagen a su cargo, obtener leña necesaria para las fogatas y para cocinar, adquirir un toro joven para el sacrificio, etc. En realidad, estas actividades son desarrolladas por los ayudantes de los mayordomos, los que no gozan del mismo prestigio e importancia de los topiles de la jerarquía civil. Los topiles, como subordinados a la jerarquía civil, cuentan con una vara de mando y, bajo órdenes del gobernador o el consejo, pueden realizar arrestos, confiscar bienes, etc. En cambio, los ayudantes de los mayordomos no tienen ninguna de estas atribuciones (Weigand, 1992) ${ }^{29}$ (Cuadro 3).

Cuadro 3. Ejemplo de las jerarquías religiosas de San Sebastián, Tuxpan, Santa Catarina y Guadalupe Ocotán.

\begin{tabular}{|c|c|c|c|}
\hline $\begin{array}{c}\text { San Sebastián } \\
\text { (Escalante Carbajal 2010) }\end{array}$ & $\begin{array}{c}\text { Tuxpan } \\
\text { Fabila (1959) }\end{array}$ & $\begin{array}{c}\text { Santa Catarina } \\
\text { (Fabila, 1959) }\end{array}$ & $\begin{array}{l}\text { Guadalupe Ocotán } \\
\text { (Téllez 2005, 2011) }\end{array}$ \\
\hline Cristo grande & Ratontita (Tuxpan) & Cristo Jesús (2) & $\begin{array}{l}\text { Virgen de Guadalupe (Primer } \\
\text { mayordomo) }\end{array}$ \\
\hline Cristo pequeño & Turquizata (Ocota) & María de Guadalupe & $\begin{array}{l}\text { Santo Cristo (Segundo } \\
\text { mayordomo) }\end{array}$ \\
\hline $\begin{array}{c}\text { San Sebastián grande y San } \\
\text { Sebastián chico }\end{array}$ & Shacozapa (Techalotita) & Señor San José & $\begin{array}{l}\text { Priostes del Primer mayordo- } \\
\text { mo (2) }\end{array}$ \\
\hline San José & Yucuita (Santa Gertrudis) & Santa Catarina & $\begin{array}{c}\text { Priostes del Segundo mayor- } \\
\text { domo (2) }\end{array}$ \\
\hline Virgen de Guadalupe & Mucutarri (San Sebastián) & $\begin{array}{c}\text { Santita (no saben } \\
\text { el nombre de la imagen) }\end{array}$ & $\begin{array}{l}\text { Esposa de cada uno de los } \\
\text { mayordomos. }\end{array}$ \\
\hline La Señora (Tanana) & & & $\begin{array}{c}\text { Esposa de cada uno de los } \\
\text { Priostes }\end{array}$ \\
\hline
\end{tabular}


En Guadalupe Ocotán esta jerarquía religiosa está encabezada por dos funcionarios principales, los mariatumatsixi: uno dedicado a la Virgen de Guadalupe o Tanana y otro dedicado al Santo Cristo o Xaturi $^{30}$. En Guadalupe Ocotán estos mayordomos se designan como puriyustil Mayordomo primero o mayordomo derecho, y teputaril Mayordomo segundo o mayordomo izquierdo, respectivamente. Cada uno de estos mayordomos cuenta con dos ayudantes que reciben los mismos nombres: $p u-$ riyusti y teputari (Watanabe, 1997; Téllez, 2005, 2011c). Al igual que los 'itsikate, cada uno de estos funcionarios debe contar con una compañera, su esposa. Desde mediados del siglo XX, cuando los religiosos tomaron posesión de la capilla y la misión, los mayordomos realizan sus actividades en el kaliwei/Casa de gobierno y trabajan de manera conjunta con el gobernador indígena, quien encabeza todas las ceremonias ligadas a este recinto guiado por el kawiteru y un mara'akame. El papel de los mariatumatsixi consiste en mantener limpio el $\mathrm{ka}$ liwei y, principalmente, el altar en que se encuentra la imagen de la Virgen de Guadalupe, además de resguardar los bienes obsequiados a los santos, especialmente durante las celebraciones de Semana Santa (Watanabe, 1997).

La mayoría de las reliquias dedicadas a los santos se encuentran en los tsamurite, estuches de palma donde se guardan telas que sirven para cubrir las imágenes de los santos durante la Semana Santa, algunas imágenes religiosas, monedas, flechas, flores de papel y listones de colores que se atan a la cornamenta de los toros que van a ser sacrificados a la Virgen, etc. (Imagen 2). Cada mayordomo tiene un tsamuri bajo su resguardo. Sin embargo, las ofrendas realizadas en la capilla (dinero, carne, semillas, telas, etc.) son administradas directamente por los misioneros. En el pasado, las mayordomías de esta gobernancia eran renovadas cada doce de diciembre, en la capilla, aunque el proceso de reorganización por el que ha atravesado la jerarquía cívico-religiosa ha modificado esta fecha y son designados al mismo tiempo que la jerarquía civil.

\section{Conclusiones}

El análisis de los sistemas de cargos civiles y religiosos ha sido un elemento fundamental en el estudio de las sociedades mesoamericanas. A pesar del extenso corpus etnográfico iniciado por Lumholtz, Diguet, Preuss y Zingg, existe un relativo vacío en cuanto al análisis de las jeraquías tradicionales en la zona Nayarita, ocupada por Coras, Huicholes, Tepehuanos y Mexicaneros. En las últimas décadas ha cobrado especial importancia el estudio del complejo mitote realizado en los templos y patios ceremoniales de la región, así como las jerarquías y la parafernalia asociadas a ellos, especialmente entre los huicholes (Neurath, 1998, 2002; Gutiérrez del Ángel, 2002a, 2002b, 2010; Reyes Valdéz, 2006; Guzmán, 2002).

Este vacío se extiende particularmente al análisis de las jerarquías civiles y religiosas instituidas durante el periodo colonial, a tal grado que prevalece una visión exótica e igualitaria sobre la cultura huichola, además de que algunos autores consideran que hay pocos trabajos relacionados con estas jerarquías (Pacheco Ladrón de Guevara, 1997, 1999; Vázquez Violante, 2010). No obstante la revisión de las fuentes de origen colonial, los informes misioneros y administrativos a mediados del siglo XIX, así como la de los datos etnografícos disponibles desde finales del mismo siglo, nos permite darnos cuenta de la forma en que las estructuras de origen prehispánico (ligadas a la estructura Tukipa) y colonial (las jerarquías civiles y religiosas) han logrado mantener su importancia política y ceremonial a pesar de su interacción con las estructuras creadas por el Estado mexicano a nivel regional y nacional (como las delegaciones municipales y los Comisariados de Bienes Comunales).

En este trabajo he resaltado los estudios enfocados en las estructuras civiles y religiosas de los huicholes. Sin embargo debe señalarse que, en cuanto a su relación con la estructura Tukipa, representada por los kawiterutsixi, nos encontramos con una especie de gobierno dual (Carrasco, 1979), en que estos personajes, descendientes de los antiguos cacicazgos de la región, lograron mantener su autoridad política y ceremonial, especialmente a nivel de sus respectivos distritos. Esto se extiende a su capacidad para designar, en conjunto, a los funcionarios de las jerarquías civiles y religiosas de cada comunidad. Por otro lado, es necesario profundizar en el análisis de las relaciones que han permitido que estas estructuras tradicionales mantengan su posición a pesar de los cambios y adaptaciones que han tenido que asumir para enfrentar las presiones sobre su organización política y territorial (Weigand, 1992; Weigand y García 2000, 2002a; Téllez, 2011a, 2011b, 2011c). 
Ante la creciente importancia de los cargos de carácter agrario y municipal, así como la creación de comisiones locales (a cargo del manejo del agua, escuelas, etc.), debe prestarse atención a la forma en que estos proporcionan un tipo de prestigio político y acceso a recursos difíciles de conseguir desde la estructura comunitaria tradicional. Esto nos lleva a considerar aquellos casos en que las jerarquías tradicionales han visto disminuido su poder efectivo sobre algunos miembros de la comunidad (espceialmente profesionistas y migrantes) y los representantes civiles y agrarios, lo que los acerca a lo que Chance (1990) define como un sistema de transición y, en casos extremos, en un sistema esencialmente religioso.

En esta situación, las jerarquías tradicionales mantienen parte de su autoridad en el ámbito ceremonial y, en cierto sentido, moral de la comunidad, pero ven disminuida su capacidad para tomar decisiones e incidir en la administración de justicia o la defensa de los derechos sobre su territorio y el acceso a sus recursos. Esto repercute en el debilitamiento de las estructuras y normas tradicionales, afectando la relativa autonomía de estas comunidades, aunque pueden establecerse mecanismos para tratar de reintegrar a las jerarquías tradicionales parte de su anterior prestigio y autoridad.

En este sentido, es preciso revisar casos como el de Guadalupe Ocotán, donde las sanciones ceremoniales, ejercidas por los kawiterutsixi, los mara'akate y ancianos que han formado parte de las jerarquías tradicionales, han forzado a las autoridades agrarias y municipales a reconocer su importancia y participar en las actividades dirigidas por ellas, además de ritualizar sus propias funciones, lo que no excluye la posibilidad de que continúen los conflictos entre estos niveles de autoridad (Téllez, 2011c).

Por otra parte, es preciso describir el surgimiento de nuevas autoridades tradicionales en asentamientos ajenos al contexto de las comunidades de la zona del río Chapalagana, especialmente en la zona Tecualhuichol del estado de Nayarit, donde los discursos oficiales reconocen la existencia de las formas de gobierno tradicional (Mapa 2). Sin embargo, este reconocimiento tiene serias limitaciones, pues no se entiende cabalmente la importancia de las jerarquías cívico-religiosas en la vida comunitaria $\mathrm{y}$, por tanto, no se le reconoce ninguna importancia política a estas instituciones. Por el contrario, las jerarquías tradicionales son percibidas como un elemento ornamental, cuya presencia es obligatoria en ciertos actos organizados por las dependencias gubernamentales. Eso sin olvidar la influencia de diferentes denominaciones religiosas que se contraponen a los patrones de organización comunitaria y que se niegan a participar en los sistemas de cargos civiles y religiosos, a la vez que generan nuevas situaciones sociales dignas de estudio.

\section{Referencias Citadas}

Aguirre Beltrán, Gonzalo

1991a (1953) Formas de gobierno indígena, México, Universidad Veracruzana/ Instituto Nacional Indigenista/ Gev/Fondo de Cultura Económica.

1991b Regiones de refugio. El desarrollo de la comunidad y el proceso dominical en Mestizoamérica, México, Universidad Veracruzana/Instituto Nacional Indigenista/Gev/Fondo de Cultura Económica.

Anguiano, Marina

1974 "El cambio de varas entre los Huicholes de San Andrés Cohamiata, Jalisco", en Anales de Antropología, II, pp. 169-187.

Arcos, Ángeles

1998 Las velas de Tateikietari... invocando la lluvia y la lucha de un pueblo, tesis de Maestría en Desarrollo Rural, Universidad Autónoma Metropolitana-Xochimilco.

Arias y Saavedra, Antonio

1975 "Franciscan report on the Indians of Nayarit, 1673" (introducción de Kieran McCarthy, OFM; traducción de Dan S. Matson), en Ethnohistory, núm. 22, pp. 193-222.

1986 (1673) "Información rendida por el P. Antonio Arias y Saavedra, acerca del estado de la Sierra del Nayarit, en el siglo XVII", en Alberto Santoscoy. Obras completas, vol. II, Guadalajara, Jalisco, Gobierno del Estado de Jalisco, Unidad Editorial, pp. 973-989.

1990 (1673) "Información rendida en el siglo XVII por el P. Antonio Arias y Saavedra acerca del estado de la Sierra de Nayarit y sobre culto idolátrico, gobierno y costumbres primitivas de los coras", en Thomas Calvo (ed.), Los albores de un nuevo mundo: siglos XVI y XVII, México, Centro de Estudios Mexicanos y Centroamericanos, pp. 283-309.

Thomas Calvo (ed.)

1990 Los albores de un nuevo mundo: siglos XVI y XVII, México, Centro de Estudios Mexicanos y Centroamericanos. Cancian, Frank

1989 (1965) Economía y prestigio en una comunidad maya, México, Instituto Nacional Indigenista/Consejo Nacional para la Cultura y las Artes.

1991 "El comportamiento económico de las sociedades campesinas", en Antropología económica, Stuart Platner (coord.), México, Consejo Nacional para la Cultura y las Artes/Alianza, pp. 177-144.

Campos H., Fr. Alberto OFM

1979 La evangelización de los huicholes y Guadalupe Ocotán. Algunas notas para su historia, mecanoescrito, Convento de Nuestra Señora del Refugio, Garza García, N.L. 
Carmagnani, Marcelo

1993 (1988) El regreso de los dioses. El proceso de reconstitución étnica en Oaxaca. Siglos XVII y XVIII, México, Fondo de Cultura Económica.

Carrasco, Pedro

1979 "La jerarquía cívico-religiosa en las comunidades de Mesoamérica: antecedentes precolombinos y desarrollo colonial", en Antropología política, Joseph R. Llobera (comp.), Barcelona, Anagrama, pp. 323-340.

Chance, John K.

1990 "Changes in Twentieth-Century Mesoamerican Cargo System", en Class, Politics and Popular Religion: Religious Change in México and Central America, Washington, AAA, pp. 27-42.

Chance, John K. y William B. Taylor

1985 "An Historical Perspective on the Mesoamerican CivilReligious Hierarchy”, en American Ethnologist, 12(1): 1-26.

Chevalier, François

1944 "Les municipalités indiennes en Nouvelle-Espagne (1520-1560)", en Anuario de historia del derecho español, t. XV, Madrid, pp. 352-368.

Dahlgren, Barbo

1972 (1962) "Semejanzas y diferencias entre coras y huicholes en el proceso de sincretismo", en Coras, Huicholes y Tepehuanes, Thomas B. Hinton (comp.), México, Instituto Nacional Indigenista/Consejo Nacional para la Cultura y las Artes, pp. 99-118.

De la Peña, Guillermo

1980 Herederos de promesas. Agricultura, política y ritual en Los Altos de Morelos, México, Centro de Investigaciones y Estudios Superiores en Antropología Social.

1999 New Brokers, New Ethnicities: Indigenous Intellectuals, NGO's, and the 'Neo-Liberal' State in Mexico, ponencia presentada en el panel: "The Anthropology of Politics and the Politics of Anthropology", Manchester.

Diguet, León

1992 Por tierras occidentales: entre sierras y barrancas, Jean Meyer y Jesús Jáuregui (eds.), México, Instituto Nacional Indigenista/Centro de Estudios Mexicanos y Centroamericanos.

Dow, James, 1992-1993, "Protestantismo en el campo: causas materiales del abandono de las fiestas en la Sierra Oriente de Hidalgo", en Notas Mesoamericanas (14): 123-130.

Durin, Séverine, 2001, Participación social y cambio social, ponencia presentada en el Seminario Pueblos indígenas, Estado y sociedad en México: nuevas relaciones, ¿nuevas contradicciones?, Guadalajara.

Escalante Carbajal, Kevin

2010 La construcción de la territorialidad y la identidad en los procesos rituales, la cosmovisión y la organización social: La comunidad de San Sebastián Teponahuaxtlán, una comunidad wixarika, Tesis de licenciatura, Universidad Autónoma de San Luis Potosí.

Fabila, Alfonso

1940 Las tribus yaquis de Sonora. Su cultura y anhelada autodeterminación, México, Departamento de Asuntos Indígenas.

1959 Los huicholes de Jalisco, México, Instituto Nacional Indigenista/Gobierno del Estado de México.

1978 Las tribus yaquis de Sonora. Su cultura y anhelada autodeterminación, México, Instituto Nacional Indigenista.
Gerhard, Peter

1996 (1982) La frontera Norte de la Nueva España, México, Universidad Nacional Autónoma de México.

González Navarro, Moisés

1977 (1953) Repartimientos de indios en Nueva Galicia, México, Instituto Nacional de Antropología e Historia.

Grimes, Joseph E.

1961 "Huichol economics", en América Indígena, vol. XXI, núm. 4, pp. 281-301, México.

Grimes, Joseph E. y Thomas B. Hinton

1972 (1969) "Huicholes y coras" en Coras, huicholes y tepehuanes, Thomas B. Hinton (comp.), México, Instituto Nacional Indigenista/Consejo Nacional para la Cultura y las Artes, pp. 73-97.

Gutiérrez del Ángel, Arturo

2002a "Jerarquía, reciprocidad y cosmovisión: el caso de los centros ceremoniales tukipa en la comunidad huichola de Tateikie", en Alteridades 12 (24): 75-97.

2002b La peregrinación a Wirikuta: el gran rito de paso de los huicholes, México, Instituto Nacional de Antropología e Historia/Universidad de Guadalajara.

2010 Las danzas del padre sol. Ritualidad y procesos narrativos en un pueblo del Occidente mexicano, México, Universidad Nacional Autónoma de México/ Instituto de Investigaciones Antropológicas/ Universidad Autónoma Metropolitana-Unidad Iztapalapa.

Guzmán, Adriana

2002 Mitote y universo cora, México, Instituto Nacional de Antropología e Historia/ Universidad de Guadalajara.

Herrera Guevara, Sebastián Porfirio

2013 "Memorias de la misión de San Andrés Cohamiata en el Nayarit, circa 1853-1872", en: Relaciones, 135, Verano, pp. 127-154.

Hinton, Thomas B. et al.

1972 Coras, huicholes y tepehuanes, México, Instituto Nacional Indigenista/Consejo Nacional para la Cultura y las Artes, pp. 73-97.

Jáuregui, Jesús (ed.)

1992a Bibliografía del Gran Nayar: coras y huicholes, México, Centro de Estudios Mexicanos y Centroamericanos/ Instituto Nacional Indigenista.

1998 "La investigación etnológica sobre los coras y huicholes en los últimos cincuenta años: un comentario crítico", en Antropología e historia del Occidente de México, t. I, XXIV Mesa redonda de la Sociedad Mexicana de Antropología, SMA/Universidad Nacional Autónoma de México, pp. 287-361.

Kindl, Olivia Selena

2003 La jícara huichola. Un microcosmos mesoamericano, México, Consejo Nacional para la Cultura y las Artes/ Instituto Nacional de Antropología e Historia/Universidad de Guadalajara.

Klineberg, Otto

1934 "Notes on the Huichol", en: American Anthropologist, N.S., vol. 36, julio-septiembre, pp. 450-460.

1972 "Notas sobre los huicholes", en: El peyote y los huicholes, Salomón Nahmad et al., México, Secretaría de Educación Pública (Sep-Setentas), pp. 29-52.

Knab, Tim

1981 "Artesanía y urbanización: el caso de los huicholes", en: América Indígena, vol. 41, núm. 2, pp. 231-243. 
Lemaistre, Denis y Olivia Kindl

1999 "La semaine sante huichole de Tateikie: rituel solaire et légitimation du puvoir par les sacrificies", en Journal de la Société del Americanistes, 85: 175-214.

Liffman, Paul

1996 "Reivindicación territorial y convergencia democrática de los Wixaritari (Huicholes)", en: La democracia de los de abajo en Jalisco, Jorge Alonso y Juan Manuel Ramírez (comps.), México, Universidad de Guadalajara/ Centro de Investigaciones y Estudios Superiores en Antropología Social/ CIICH-Universidad Nacional Autónoma de México/ Consejo electoral del estado de Jalisco, pp. 41-75.

1997 Representatividad y representación políticas entre los Wixaritari (Huicholes), Encuentro en la Latin American Studies Association, Guadalajara.

2000 "Gourdvines, Fires and Wixárika Territoriality" en: Journal of the Southwest 42(1): 129-165.

2011 Huichol Territory and the Mexican Nation: Indigenous Ritual, Land Conflict, and Sovereignty Claims, Tucson, University of Arizona Press.

2012 La territorialidad Wixarika y el espacio nacional. Reivindicación indígena en el Occidente de México, Zamora, Mich., El Colegio de Michoacán A. C./ Centro de Investigaciones y Estudios Superiores en Antropología Social.

Lira, Andrés y Luis Muro

2000 "El siglo de la integración", en: Historia general de México, México, El Colegio de México, pp. 309-362.

Lühmann, Werner 1971 (1969) Los huicholes, Guadalajara, Ed. Et Caetera.

Lumholtz, Carl

1986a (1902) El México desconocido, México, Instituto Nacional Indigenista (2 t.).

1986b (1890) El arte simbólico de los huicholes, México, Instituto Nacional Indigenista.

Manzanares Monter, Sara Alejandra

2009 El sistema de cargos de los Xukuritkate: parentesco y poder en unca comunidad wixarika, México, Universidad Nacional Autónoma de México-Instituto de Investigaciones Antropológicas.

Mata Torres, Ramón

1970 Los huicholes, Guadalajara, Ediciones de la Casa de la Cultura Jalisciense.

Medina, Andrés

1983 "Los grupos étnicos y los sistemas tradicionales de poder en México", en: Nueva Antropología, V (20): 5-29.

2000 En las cuatro esquinas, en el centro. Etnografía de la cosmovisión mesoamericana, México, Universidad Nacional Autónoma de México.

Meyer, Jean

1984 Esperando a Lozada, México, El Colegio de Michoacán-CONACYT.

1986 "La Ley Lerdo y la desamortización de las comunidades en Jalisco", en: La sociedad indígena en el Centro y Occidente de México, México, El Colegio de Michoacán, pp. 189-211.

Neurath, Johannes

1998 Las fiestas de la Casa Grande: Ritual agrícola, iniciación y cosmovisión en una comunidad Wixarika (Tiapurie/Santa Catarina Cuexcomatitán), tesis de doctorado, Universidad Nacional Autónoma de México.
2002 Las fiestas de la Casa Grande: Procesos rituales, cosmovisión y estructura social en una comunidad huichola, México, Conaculta/Instituto Nacional de Antropología e Historia/Universidad de Guadalajara.

Ortega, José

1944 (1754) "Maravillosa reducción y conquista de la provincia de S. Joseph del Gran Nayar", en: Apostólicos afanes de la Compañía de Jesús escritos por un padre de la misma sagrada religión, México, Layac.

1996 (1754) "Maravillosa reducción y conquista de la provincia de S. Joseph del Gran Nayar", en: Apostólicos afanes de la Compañía de Jesús escritos por un padre de la misma sagrada religión, México, Centro de Estudios Mexicanos y Centroamericanos/Instituto Nacional Indigenista.

Pacheco Ladrón de Guevara, Lourdes

1997 "Los Wirrarika o huicholes", en: Etnias de Nayarit, México, Secretaría de Eucación Pública/Conafe, pp. 81-121. 1999 Nomás venimos a malcomer. Jornaleros indios en el tabaco en Nayarit, Tepic, Universidad Autónoma de Nayarit.

Pacheco Salvador, 'iritemai (Gabriel)

1997 "La forma de gobierno tradicional de los huicholes", en: La América profunda habrá de emerger, José María Muriá (ed.), Guadalajara, El Colegio de Jalisco/Vicepresidencia de la República de Bolivia, pp. 77-87.

Padilla Pineda, Mario

s/f "Sistema de cargos, intercambio ceremonial y prestigio", mecanoescrito, El Colegio de México.

Preuss, Konrad

1998 Fiesta, literatura y magia en el Nayarit: ensayos sobre coras, huicholes y mexicaneros de Konrad Teodor Preuss, Johannes Neurath y Jesús Jáuregui (eds.), México, Instituto Nacional Indigenista/Centro de Estudios Mexicanos y Centroamericanos.

Rajsbaum, Ari

1993 Huicholes, México, Instituto Nacional Indigenista/ Secretaría de Desarrollo Social.

1994 "Los Huicholes", en: Etnografía contemporánea de los pueblos indígenas de México. Región Occidental, México, Instituto Nacional Indigenista, pp. 53-107.

Reed, Karen Bárbara

1972 El INI y los huicholes, México, Secretaría de Eucación Pública/Instituto Nacional Indigenista.

Reyes Valdez, Antonio

2006 Los que están benditos. El mitote comunal de los tepehuanes de Santa María de Ocotán, México, Instituto Nacional de Antropología e Historia.

Rojas, Beatriz (comp.)

1992 Los huicholes. Documentos históricos, México, Instituto Nacional Indigenista/ Centro de Investigaciones y Estudios Superiores en Antropología Social.

1993 Los huicholes en la historia, México, Centro de Estudios Mexicanos y Centroamericanos/El Colegio de Michoacán/ Instituto Nacional Indigenista.

Roseberry, William

1989 Anthropology and Histories. Essays in Culture, History and Political Economy. New Brunswick, N. J., Rutgers University Press.

1991 "Los campesinos y el mundo", en: Antropología económica, Stuart Platner (coord.), México, Consejo Nacional para la Cultura y las Artes/Alianza, pp. 154-176. 
Santoscoy, Alberto

1986 (1890) "Nayarit. Colección de documentos inéditos, históricos y etnográficos, acerca de la sierra de ese nombre", en: Obras completas, vol. II, Guadalajara, Gobierno de Jalisco, Secretaría General, Unidad Editorial, pp. 913-989.

Shadow, Robert D.

1978 Land, Labor and Cattle: The Agrarian Economy of a West Mexican Municipio, tesis doctoral, State University of New York.

2001 "Gobierno y población en San Luis de Colotlán durante la Colonia", en: Colotlán y su región, Guadalajara, El Colegio de Jalisco/Campus Universitario del Norte, pp. 4-16.

2002 Tierra, trabajo y ganado en la región norte de Jalisco, México, El Colegio de Michoacán/ Universidad de Guadalajara.

Smith, Waldemar R

1981 El sistema de fiestas y el cambio económico, México, Fondo de Cultura Económica.

Stephen, Lynn

1990 "The Politics of Ritual: The Mexican State and Zapotec Economy", en Class, Politics and Popular religion: Religious Change in Mexico and Central America, Washington, AAA, pp. 43-60.

y James Dow (eds.)

1990 "Introduction: Popular Religion in México and Central America", en: Class, Politics and Popular religion: Religious Change in Mexico and Central America. Washington, AAA pp. 1-26.

Téllez Lozano, Víctor M.

2005 Territorio, gobierno local y ritual en Xatsitsariel Guadalupe Ocotán, tesis doctoral, Centro de Estudios Antropológicos de El Colegio de Michoacán.

2006a "Contexto histórico de los conflictos agrarios en territorio huichol", en: Memorias del Primer encuentro de especialistas sobre la región Norte de Jalisco, Centro Universitario del Norte/ Universidad de Guadalajara, pp. 237-268.

2006b La reorganización del recinto ceremonial (Tukipa) huichol de Guadalupe Ocotán, Nayarit, Informe de la investigación patrocinada por The Foundation for the advancement of Mesoamerican Studies Inc. (FAMSI), disponible en línea: www.famsi.org/reports/05083es/ index.html

2009 "Xatsitsarie y Tutsipa: un acercamiento a la reorganización del territorio Wixarika entre los siglos XVIII y XIX", en: Actas del VI Coloquio internacional de Occidentalistas: El Occidente de México, relaciones intra e interregionales, editado por el Departamento de Estudios Mesoamericanos y Mexicanos de la Universidad de Guadalajara.

2010 "La organización política y ceremonial de los huicholes en el contexto de las sociedades Nayaritas", en: Phil Weigand Moore. Reconocimiento Tenamaztle 2009, Verenice Heredia y Víctor Téllez (coords.), Centro Universitario del NorteUniversidad de Guadalajara, pp: 63-86.

2011a "Procesos de reorganización política y ceremonial en territorio huichol: el tuki de Xatsitsarie", en: Mesoamérica. Debates y Perspectivas, Zamora, El Colegio de Michoacán. 2011b "Tukipa: los recintos ceremoniales como fundamento del territorio, patrimonio histórico y cultural de los huicholes", en: La antropología y el patrimonio cultural de México. Dirección de Estudios Históricos/ Conaculta, pp: 129-187.

2011c Xatsitsarie. Territorio, gobierno local y ritual en una comunidad Huichola, El Colegio de Michoacán A. C.

2011d "Lozadistas, revolucionarios y cristeros: movimientos armados y reorganización territorial entre los huicholes", en:
Participación indígena en los procesos de Independencia y Revolución Mexicana, México, Comisión Nacional para el Desarrollo de los Pueblos Indígenas, pp. 225-248.

Torres Contreras, José de Jesús

2000 El hostigamiento a "el costumbre" huichol, Zamora, El Colegio de Michoacán/Universidad de Guadalajara.

Vázquez Violante

2010 "Armonía y poder. Autoridades tradicionales y cargos dentro de la comunidad de Tateikie, San Andrés Cohamiata", en: Phil Weigand Moore. Reconocimiento Tenamaztle 2009, Verenice Heredia y Víctor Téllez (coords.), Centro Universitario del Norte-Universidad de Guadalajara, pp. $96-102$

Velázquez, Ma. del Carmen

1961 Colotlán: doble frontera contra los bárbaros, México, Universidad Nacional Autónoma de México.

Villa Rojas, Alfonso

1955 "Los huicholes", en: Acción Indigenista 20, Boletín Mensual del Instituto Nacional Indigenista.

Vogt, Evon Z.

1983 (1976) Ofrendas para los dioses, México, Fondo de Cultura Económica.

1972 (1955) "Algunos aspectos de aculturación cora-huichol", en: Coras, Huicholes y Tepehuanes, Thomas B. Hinton (comp.), México, Instituto Nacional Indigenista/Consejo Nacional para la Cultura y las Artes, pp. 119-126.

Warman, Arturo

1988 .... venimos a contradecir. Los campesinos de Morelos y el Estado nacional, México, Secretaría de Eucación Pública/ Centro de Investigaciones y Estudios Superiores en Antropología Social.

Watanabe, Tomoko

s/f "La Semana Santa en Xatsitsarie (Guadalupe Ocotán)", proyecto de tesis de licenciatura, especialidad de Etnología, Escuela Nacional de Antropología e Historia.

1997 "La Semana Santa en Xatsitsarie (Guadalupe Ocotán)", informe de trabajo de campo, Instituto Nacional de Antropología e Historia.

Weigand, Phil

1992 Ensayos sobre el gran Nayar. Entre coras, huicholes y tepehuanos, México, Instituto Nacional Indigenista/Centro de Estudios Mexicanos y Centroamericanos/El Colegio de Michoacán.

Weigand, Phil y Acelia García de Weigand

2000 "Huichol Society before the Arrival of the Spanish", en: Journal of the Southwest 42 (1): 13-36.

Weigand, Phil y Acelia García de Weigand

2002a "La sociedad de los huicholes antes de la llegada de los españoles", en: Estudio histórico y cultural sobre los huicholes, México, Universidad de Guadalajara, pp. 43-68.

Weigand, Phil y Acelia García de Weigand

2002b "Los huicholes y su búsqueda del peyote: ¿reliquia sacra de una antigua ruta comercial?", en: Estudio histórico y cultural sobre los huicholes, México, Universidad de Guadalajara, pp. 79-91.

Zingg, Robert M.

1982 (1938) Los huicholes. Una tribu de artistas, México, Instituto Nacional Indigenista (2 t.).

1998 La mitología de los huicholes, Jay C. Fikes, Phil C. Weigand y Acelia García de Weigand (eds.), Zamora, El Colegio de Michoacán/El Colegio de Jalisco/Secretaría de Cultura de Jalisco. 


\section{Notas}

1 Las primeras menciones sobre estos recintos, sus jerarquías y prácticas ceremoniales asociadas se inicia a finales del siglo XIX y principios del siglo XX con los trabajos de Lumholtz (1986a, 1986b), Diguet (1992) y Preuss (1998). Posteriormente Zingg haría importantes observaciones etnográficas complementadas por una revisión de la mitología huichola (1982, 1998). En los años sesenta, Weigand (1992) documentaría los procesos de recomposición resultantes de la Revolución y la Cristiada. Para un análisis más detallado de las jerarquías relacionadas con la estructura tukipa contemporáneas pueden revisarse las obras de Neurath, que maneja una perspectiva etnohistórica $(1998,2002)$, Gutiérrez del Ángel (2002a, 2002b) y Manzanares, (2009). Un enfoque etnohistórico, que difiere en algunos aspectos de la propuesta de Neurath, se aprecia en los trabajos de Weigand y García $(2000,2002 a)$ y Téllez $(2006 b, 2011 a$, 2011b, 2011c).

2 Desde la época colonial, los misioneros denominaron como kaliwei (del nahuatl huey calli o casa grande) a los templos de la zona Nayarita (Ortega, 1944, 1996; Neurath, 1998, 2002; Téllez, 2005, 2011c). Para el siglo XIX este término se extendió a los xirikite o adoratorios dedicados a los antepasados que se encuentran tanto en los patios ceremoniales de los recintos Tukipa como en los ranchos de cada distrito ceremonial (Rojas, 1992; Téllez 2005, 2006b, 2011a, 2011b, 2011c). En Guadalupe Ocotán el término kaliwei se aplica también a la katsariana o casa real, especialmente cuando se habla en español.

3 Entre estos recintos menciona los de Santa Catarina, Ratontita, Multita, Techalotita, San Andrés Cohamiata, Guadalupe Ocotán, Las Latas, Pochotita, Ocota, Mucushatá (sic) o Tierra Amarilla y uno que se estaba construyendo en San Sebastián. Una posibilidad es que más que construcción se refiriera a la renovación del recinto Tukipa de San Sebastián. Posteriormente, Weigand (1992) indicaría que no se había realizado fiesta alguna en él desde 1963 hasta la época en que realizara su trabajo de campo, entre 1966 y 1969.

4 En este texto me referiré específicamente a los textos: "Grupos cooperativos de trabajo en actividades de subsistencia entre los indios huicholes de la gobernancia de San Sebastián Teponahustlán, municipio de Mezquitic, Jalisco", pp. 33-104 (Publicado originalmente en 1972); "El papel de los indios huicholes en las revoluciones del Occidente de México", pp. 121-130 (1977); "Estructura social y económica contemporánea", pp. 131-151 (1978) y "Aculturación diferencial entre los indios huicholes", pp. 153-174, (1981).

5 "El papel de los indios huicholes ...".

6 Ya que para esta época se encontraba destruido el recinto ceremonial de Guadalupe Ocotán, el templo señalado por Fabila en la nota 3 corresponde a este espacio.

7 En Guadalupe Ocotán, entre 2004 y 2005, logró reconstruirse el recinto tukipa gracias a la unión de las autoridades tradicionales, civiles y agrarias de la comunidad. Sin embargo, la falta de continuidad en los proyectos, ocasionada en parte por el faccionalismo político, ha impedido la reorganización de la jerarquía ceremonial asociada a este recinto (Téllez, 2011a, 2011c).

8 "Aculturación diferencial entre los indios huicholes".
9 En esta época Sebastián Antonio Victorino, indio principal y cacique de Santo Domingo Tenzompa era gobernador y capitán a guerra de Tenzompa, San Cristobal de la Navidad y San Nicolás -pertenecientes a la jurisdicción de San Luis Colotlán-y prestó valiosos servicios a los conquistadores. En 1731, debido a su celo en la destrucción de "los vicios públicos y el detestable de la idolatría", fray Nicolás de Revilla, cura de Huejuquilla, sugirió que su autoridad se extendiera hacia los pueblos San Andrés, Santa Catarina, San Sebastián, Nostique, Ascapulco y Camotlán (Rojas, 1992: 66).

10 Este hecho fue contemplado en su momento por Zingg (1982: 137-138).

11 "Estructura social y económica contemporánea".

12 "Grupos cooperativos de trabajo...".

13 "Estructura social y económica contemporánea", "Aculturación diferencial...".

14 Vázquez Violante (2010) indica que en San Andrés Cohamiata existen dieciséis agencias municipales creadas a partir de los años sesenta.

15 "Estructura social y económica contemporánea".

16 "Estructura social y económica contemporánea".

17 Ídem.

18 Ídem.

19 Ídem.

20 Ídem.

21 Zingg analiza la importancia de los sueños como revelaciones de los dioses que pueden manifestarse tanto a los mara'akate o cantadores como a la gente común (Zingg, 1982). Políticamente hablando, el sueño está revestido de gran importancia en la elección de las autoridades tradicionales, hecho que se conjuga con la búsqueda del consenso entre estos funcionarios, el kawiteru y los mara'akate en cuanto a las aptitudes y la disposición de las personas soñadas para asumir estas responsabilidades (Téllez, 2011c).

22 "Estructura social y económica contemporánea".

23 Escalante Carbajal (2010) contabiliza de cuatro a diez topiles entre los que corresponden a las autoridades civiles y las religiosas.

24 Esta imagen secundaria no sustituye a la "original" resguardada en la capilla, sino que es considerada como su representante o hermana menor y recibe el mismo respeto. La imagen principal se considera doblemente sagrada: en primera por haber sido dedicada especialmente para Guadalupe Ocotán por el obispo de Zacatecas y, en segunda, por su unión ceremonial con las varas de mando al reorganizarse esta gobernancia en los años treinta.

25 Zingg se explica esta situación por el tamaño de la localidad, aunque es necesario considerar la coyuntura histórica que dio origen a esta gobernancia en las últimas décadas del siglo XIX y los movimientos armados previos a la época en que desarrolló su trabajo de campo. Además, en su trabajo existen referencias a la enemistad entre San Sebastián y Tuxpan de Bolaños durante el periodo revolucionario (Zingg, 1982, Tomo I: 375). Aunque podemos pensar en un proceso similar al de Guadalupe Ocotán, sería necesario documentar la historia de Tuxpan para comprender la asociación de la casa real de Tuxpan como recinto ceremonial en esa época.

26 "Estructura social y económica contemporánea". 
27 Memorias de la misión de San Andrés Cohamiata en el Nayarit, Archivo Histórico de la Arquidiócesis de Guadalajara, Gobierno, Parroquias-Tepic, 1657-1799, no. de exp. 25, caja 1, 6 ff (Herra Guevara, 2013).

28 En esta ocasión Lumholtz mencionaba que solo había cuatro imágenes religiosas en Santa Catarina.

29 "Estructura social y económica contemporánea”, pp. 131-151.
30 Zingg (1998) hace notar que la Virgen de Guadalupe es identificada en Tuxpan de Bolaños como Werika Uimaru: Águila joven o bonita. Tanana puede ser un término familiar, pues está ligado a términos de parentesco, aunque no he podido definir a cuál corresponde. Otra forma de llamar a la Virgen es Warupi, adaptación del nombre original al huichol. Mientras tanto, Xaturi es la forma utilizada en huichol para decir Santo. 